\title{
The Possibilities to Reduce Arc Flash Exposure with Arc Fault Eliminators
}

\author{
Karol Nowak*, Jerzy Janiszewski and Grzegorz Dombek $\mathbb{C}$
}

Citation: Nowak, K.; Janiszewski, J.; Dombek, G. The Possibilities to Reduce Arc Flash Exposure with Arc Fault Eliminators. Energies 2021, 14, 1927. https://doi.org/10.3390/ en14071927

Academic Editor: Pavol Bauer

Received: 15 February 2021

Accepted: 29 March 2021

Published: 31 March 2021

Publisher's Note: MDPI stays neutral with regard to jurisdictional claims in published maps and institutional affiliations.

Copyright: (c) 2021 by the authors. Licensee MDPI, Basel, Switzerland. This article is an open access article distributed under the terms and conditions of the Creative Commons Attribution (CC BY) license (https:// creativecommons.org/licenses/by/ $4.0 /)$.
Institute of Electric Power Engineering, Poznan University of Technology, Piotrowo 3A, 60-965 Poznan, Poland; jerzy.janiszewski@put.poznan.pl (J.J.); grzegorz.dombek@put.poznan.pl (G.D.)

* Correspondence: karol.nowak@put.poznan.pl; Tel.: +48-61-665-2584

Abstract: This paper presents a method to limit the arc energy and hence the hazard risk category value according to IEEE 1584 by using a system of two oppositely connected multi-sectional thyristor branches. A test circuit for testing the effectiveness of a thyristor arc eliminator was designed and constructed. Arc ignition inside electrical switchgear can be a source of danger for technical personnel. The arc energy calculated according to the algorithms in IEEE 1584 can be significantly reduced by using multi-sectional arc eliminator MSAE. For the actual measuring object, the calculation of the hazardous arc flash zone and the hazard category was carried out for the system not equipped with an arc eliminator, and then the same was performed in a system with an arc eliminator. In parallel, the pressure inside the closed polyvinyl chloride (PVC) electrical box enclosure was measured and then compared with the calculated pressures that could occur during an arc fault. It was found that a Multi-Sectional Arc Eliminator (MSAE) effectively protects devices supplied from low voltage networks against the effects of short circuit or arc fault, such as the sudden increase of gas pressure inside the switchboard, which may cause it to break, significantly reduce the loss of electrode material, limit the spread of hot electrode material outside the switchgear, and also significantly reduces the energy of the electric arc.

Keywords: arc eliminator; arc protection; IEEE 1584; arc fault energy; the pressure of arc gas

\section{Introduction}

For many years, the term "electric arc" has been used in the electrical technical vocabulary. Since then, making electric arc calculations has remained a challenge for many power systems engineers and designers. Calculating incident energy levels and arc flash boundary distances to estimate the hazard risk category HRC [1] to which a worker would be exposed when working with electrical equipment is not easy. The calculations of the electric arc can tell us a lot about the behavior of the system in the short-circuit state [2]. They also give us an excellent opportunity to optimize the system in terms of safety and, above all, to try to prevent the occurrence of a hazard.

"Guide for Performing Arc-Flash Hazard Calculation" is known as the IEEE 1584 study [1-5]. This document includes algorithms for calculating the arc energy, the Flash Protection Boundary FPB, and the algorithms for calculating the value of the short-circuit current in the short-circuit circuit during the arc burning, verified by measurement results [6-9]. When an electric arc is generated, the electric energy supplied from the outside is converted into the incident energy, defined as its density on the unit surface at a given distance from the source. The density of this energy is expressed in joules (or calories) per square centimeter $\left(1 \mathrm{inch} / \mathrm{cm}^{2}=4.184 \mathrm{~J} / \mathrm{cm}^{2}\right)[10,11]$. Very often, arc faults occur as a result of improper operation of switchgear devices, poor design solutions, or environmental conditions in which electrical devices operate [12-14].

The consequence of an emergency arc is the appearance in the vicinity (up to several meters) from the arc source [15-19]: 
- a very high temperature,

- a blinding flash of light,

- the rapidly spreading plasma and hot air surrounding the discharge,

- shock wave with high-pressure impulse,

- $\quad$ high-intensity sound wave,

- ejection of hot shards and molten metal particles in all directions,

- large amounts of toxic gases.

The consequence of these phenomena is the destruction of equipment elements located near the arc [20] and the risk of health and life to the operating personnel [21,22]. It should be noted that a person does not have to touch anything to be injured by an electric arc. In the event of the conscious undertaking of live work on elements of electric circuits by a human being, the protection is much more difficult, and the type of protection must be preceded by a thorough analysis of the electric arc hazard category [23,24]. The result of such analysis is the determination of the arc incident energy value and the flash protection boundary FPB. Consequently, it is important how the arc hazard risk category can be reduced if the analysis shows that under normal conditions it is very large or when it is forbidden to perform any work under voltage [1,2,7].

The reduction of arc burning time and its fast elimination using a Multi-Sectional Arc Eliminator (MSAE) has been described in detail in $[25,26]$. The results of the conducted experiments have shown that for a resistive receiver, the electric arc is extinguished in less than $1 \mathrm{~ms}$. The shortening of the arc time results in the reduction of the arc energy. The authors decided to check the effectiveness of MSAE in relation to the guidelines from the IEEE 1584 "Guide for Performing Arc-Flash Hazard Calculation" [1-5]. The experimental tests and mathematical calculations presented in the article allow to estimate the hazard categories in systems equipped with MSAE and those equipped with standard, commonly used protection devices. In addition, the authors focused on measuring the pressure inside a hermetically closed electrical box in which an electric arc burned. The shortening of the arc time (with the use of MSAE) undoubtedly results in a lower pressure increase inside the electrical box and thus the likelihood of the installation box casing bursting. Opening the installation junction box in which the electric arc burns is very dangerous. The heated parts of the electrodes coming out pose a real danger to people in the vicinity and can also ignite materials in the vicinity and cause a fire. The voltage, current and pressure waveforms recorded and presented in the article have been enriched with photographic recording by means of a high-speed camera. The photographic record allows the precise analysis of electric arc ignition, its development and extinction as a function of time.

This paper is organized as follows: Section 2 describes the arc incident energy estimation method based on the "IEEE 1584 Guide for Performing Arc-Flash Hazard Calculations". On this basis, the Hazard Risk Category HRC is determined. Section 3 describes research object and methodology. Section 4 describes the method of determining the energy balance of an electric arc. In this section, the operation of the MSAE system is explained for further analysis. Section 5 describes an approximate calculation of the pressure resulting from the ignition of an electric arc inside a closed electrical installation box. Section 6 presents the exact results of the experiments with MSAE. There are presented oscillograms of current and voltage waveforms recorded during the extinguishing of the electric arc. Additionally, photos recorded with a fast camera showing the moment of ignition and extinction of the electric arc are provided. Section 7 describes the comparison of the calculated values of pressure in a closed electric can with the measured values recorded during the experiment. Section 8 presents the calculation results of the hazard risk category in a circuit without an arc eliminator and in a circuit equipped with a high-speed solid-state arc eliminator MSAE. Finally, Section 9 presents our conclusions.

\section{Electric Arc Hazard Risk Category}

The electric arc hazard risk category is closely related to the arc energy value. There are several methods $[4,5,27-29]$ using which it is possible to estimate the value of this 
energy and other parameters characterizing the effects of the arc at the site of analysis. One of the most universal and allowing to obtain results considered to be the most consistent with reality is the method described in the "IEEE 1584 Guide for Performing Arc-Flash Hazard Calculations". According to the recommendations included in the aforementioned study $[1,2,4,5,30]$, the arc incident energy density (expressed in $\mathrm{J} / \mathrm{cm}^{2}$ ) can be calculated from the equation:

$$
E=4.184 \cdot C_{f} \cdot E_{n} \cdot\left(\frac{t}{0.2}\right) \cdot\left(\frac{610^{x}}{D^{x}}\right)\left(\mathrm{J} / \mathrm{cm}^{2}\right),
$$

where $C_{f}$ is a calculation factor equal to 1.5 for voltages below $1 \mathrm{kV}$ and 1 for voltages above $1 \mathrm{kV}, E_{n}$ is normalized incident energy $\left(\mathrm{J} / \mathrm{cm}^{2}\right)$ (from Equation (3) below), $t$ is arc duration (s), $D$ is a distance from the worker's torso to the source of the arc ( $\mathrm{mm})$, and $x$ is a distance exponent specified in Table 1.

Table 1. Equipment type and his distance exponent $x$.

\begin{tabular}{cc}
\hline Equipment Type & Distance Exponent $\boldsymbol{D}$ \\
\hline Low voltage $(0.208-1 \mathrm{kV})$ open air & 2.000 \\
Low voltage $(0.208-1 \mathrm{kV})$ switchgear & 1.473 \\
\hline
\end{tabular}

The normalized arc energy $E_{n}(\mathrm{~J} / \mathrm{c}$ contained in Equation (1) is calculated assuming the arc duration time of $0.2 \mathrm{~s}$ (and the distance between the employee's body and the arc source is $610 \mathrm{~mm}$ ) from the equation:

$$
\log _{10} E_{n}=K_{1}+K_{2}+1.081 \cdot \log _{10} I_{a}+0.0011 \cdot G\left(\mathrm{~J} / \mathrm{cm}^{2}\right),
$$

After conversion, we get:

$$
E_{n}=10^{K_{1}+K_{2}+1.081 \cdot \log _{10} I_{a}+0.0011 \cdot G}\left(\mathrm{~J} / \mathrm{cm}^{2}\right),
$$

where $I_{a}$ is a arcing current $(\mathrm{kA}), K_{1}$ is a coefficient equal to -0.555 when the analyzed object is closed in a casing and -0.792 when the arc burns in open space, $K_{2}$ is a coefficient equal to 0 when the analyzed system is not grounded and -0.113 for a grounded system, and $G$ is a distance between current paths in the analyzed device (arc gap) (mm).

After calculating the value of the incident energy $E$ and converting it into values expressed in $\left(\mathrm{cal} / \mathrm{cm}^{2}\right)$, it is possible to determine the category of electric arc hazard and propose employee protection measures adequate to the level of risk. Table 2 lists the arc incident energy levels and the corresponding hazard risk categories.

Table 2. Arc incident energy values and hazard risk categories $[1,2,4,5]$.

\begin{tabular}{cc}
\hline Arc Incident Energy $\left(\mathrm{cal} / \mathrm{cm}^{2}\right)$ & Hazard Risk Category \\
\hline $0-1.2$ & 0 \\
$1.2-4.0$ & 1 \\
$4.0-8.0$ & 2 \\
$8.0-25.0$ & 3 \\
$25.0-40.0$ & 4 \\
\hline
\end{tabular}

If the arc incident energy is calculated to be greater than $40 \mathrm{cal} / \mathrm{cm}^{2}$, all live work is prohibited as there are no measures in place to protect the worker from the effects of such an arc. In this situation, it is necessary to take measures to reduce the arc energy value, and thus reduce the hazard risk category.

The Flash Protection Boundary (FPB) is the distance during the incident energy of an event is $1.2 \mathrm{cal} / \mathrm{cm}^{2}$, which is the amount of heat needed to cause burns of at least a 
second degree. The distance of the border of the arc damage zone can be calculated from the equation:

$$
D_{B}=\left[4.184 \cdot C_{f} \cdot E_{n} \cdot\left(\frac{t}{0.2}\right) \cdot\left(\frac{610^{x}}{E_{B}}\right)\right]^{\frac{1}{x}}(\mathrm{~mm}),
$$

where $D_{B}$ is a flash protection boundary $(\mathrm{mm})$, and $E_{B}$ is the desired incident energy at the boundary (usually $1.2 \mathrm{cal} / \mathrm{cm}^{2}$ ).

\section{Research Object and Methodology}

The experimental test was performed in a model system powered from a low voltage power grid. The arc generator (source of the arc) is placed in the surface-mounted junction box shown in Figure 1. The electrical junction box is made of thermoplastic material, which is characterized by high resistance to mechanical impact. The degree of protection provided by the junction box is International Protection (IP) Rating 55. The rubber seal and grommets (membranes) enable the protection level to be maintained at the level assumed by the producer. The actual dimensions of the can are $81.5 \times 81.5 \times 45.3 \mathrm{~mm}$. According to the manufacturer's data, the junction box may operate within the temperature range from $-25^{\circ} \mathrm{C}$ to $+85^{\circ} \mathrm{C}$, and its resistance to the glow wire test is $650{ }^{\circ} \mathrm{C}$. The electrical junction box will be referred to as the electrical switchgear or junction box in the rest of this paper. The lockable cover and rubber membranes, in addition to sealing, indirectly protect against sudden pressure increase inside the switchgear (during an arc fault) and prevent catastrophic explosion in case of its excessive increase. Figure 1 show the view of the junction box housing the experimental arc disturbance source. Wires led into the interior of the can through conduits made of polyvinyl chloride (PVC). An electric arc detector was placed in one of the pipes. A filter made of plastic with the high light transmission (glass filter) provided insulation between the flash detector and the electrodes of the arc source. Next to the flash detector, a series $21 \mathrm{G}$ pressure sensor (Keller, Winterhur, Switzerland) was installed. Parameters of used pressure sensor was shown in Table 3.

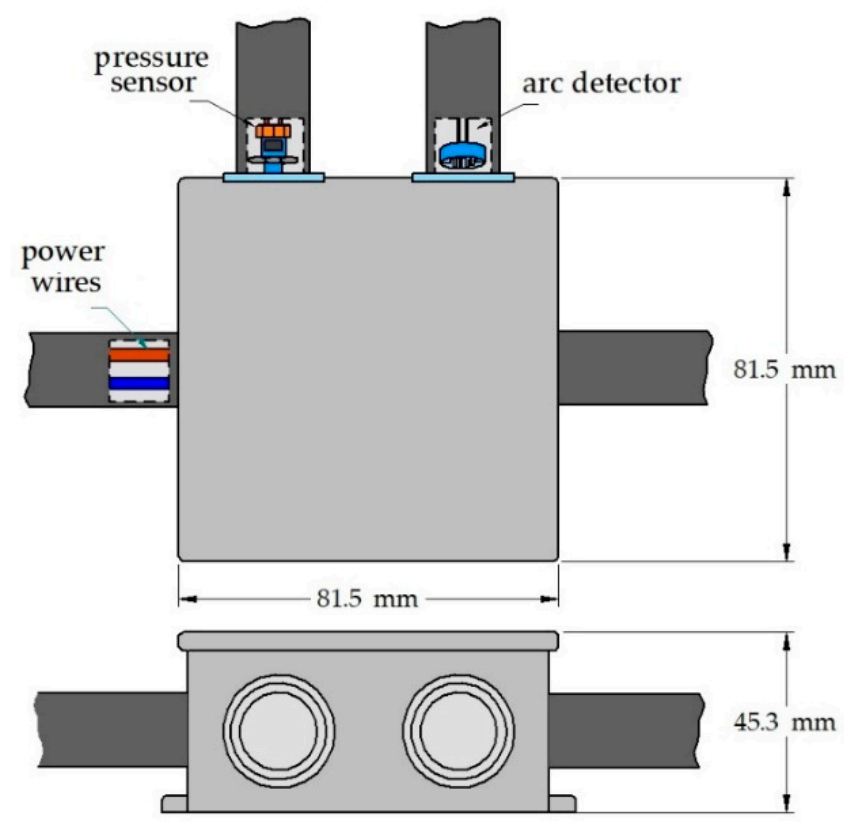

Figure 1. Electrical installation box which is a housing for an arc fault source. 
Table 3. Parameters of the Keller 21G pressure sensor (Adapted from [31]). Reproduced from [31], Keller: 2020.

\begin{tabular}{cc}
\hline Parameters & Value \\
\hline Types & Absolute or sealed gauge \\
Pressure ranges & from 0 to 5 bar \\
Electrical configuration & 2 wire \\
Output & from $4 \mathrm{~mA}$ to $20 \mathrm{~mA}$ \\
Excitation & from $8 \mathrm{~V}$ to $28 \mathrm{~V}$ \\
Linearity (BSFL) & Typical $0.25 \% \mathrm{FS}$ \\
Error band & from $-40{ }^{\circ} \mathrm{C}$ to $80^{\circ} \mathrm{C}$ typical $1.0 \% \mathrm{FS}$ \\
\hline
\end{tabular}

The measuring part of the sensor through a sealing rubber diaphragm was placed inside the installation box. Figure 2 shows a model source of the emergency arc affected by the arc disturbance. The figure shows a burning electric arc and mass emission of the electrode material in the form of glowing drops.

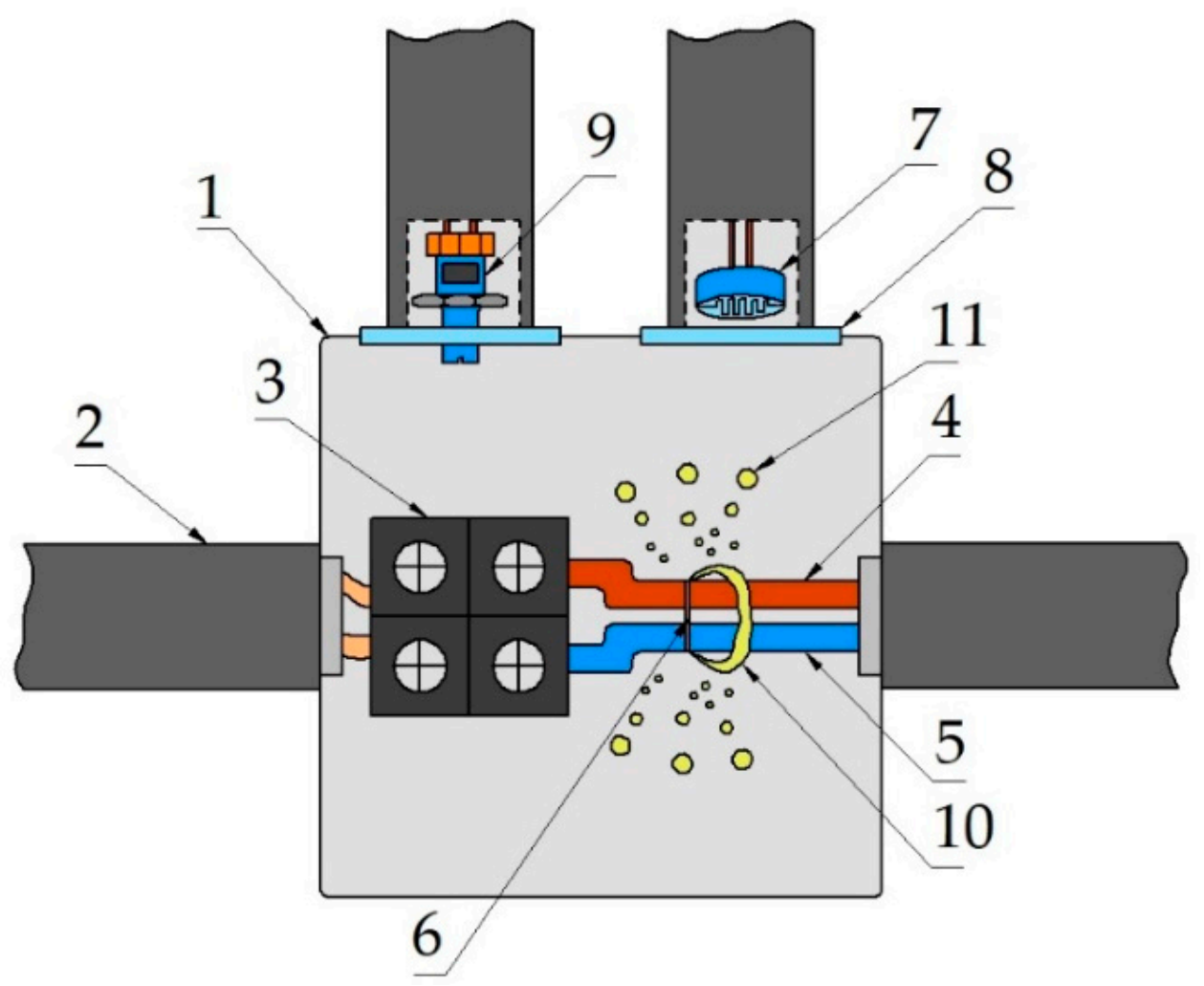

Figure 2. Construction of the arc generator: 1-Surface mounted electrical junction box; 2-PVC tube for electrical installations $(\varphi=16 \mathrm{~mm}$ ) for entry and exit of the supply lines, as well as sensors; 3-Terminal strip for quick replacement of the arc generator electrodes; 4 -Phase power wire; 5-Neutral power wire; 6-Fusible wire initiating the ignition of the arc; 7-Arc flash detector; 8-Glass, insulating protection of the flash detector; 9-Gas pressure sensor inside the electrical junction box; 10-Arc fault; 11-Drops of glowing material, which constitute the weight loss of the measuring electrodes.

\section{The Balance of Energy Supplied to the Electric Arc Fault}

The heat energy released in the emergency electric arc can cause, and often causes, significant damage to equipment inside and outside the area affected by the arc fault. It is also a serious threat to people and devices near an electric arc. If an electric arc occurs in the electrical switchgear or electrical junction box, there are mechanical risks associated with the possibility of tearing the casing walls (unsealing the housing) or breaking other switchgear elements (doors, partitions, etc.). It is related to the sudden increase in pressure 
inside the place affected by the electric arc, proportional to the energy absorbed by the arc from the electrical supply network (Equation (6)).

Figure 3 shows the equivalent diagram of the tested AC circuit in which the electric arc was ignited between the electrodes of the arc generator and an example of sequential taking over current by shunting paths in the order in which thyristors are triggered. The MSAE [25,26] presented in Figure 3a is a multi-sectional arc eliminator which belongs to the family of bypass circuits affected by the failure. Its task is to quickly eliminate interference (electric arc, emergency current), preventing further development of irregularities. The system's operation consists in the sequential taking over the current by multi-sectional cascading bypass branches when a failure occurs in the protected electrical circuit (Figure 3b). The undoubted advantage of this solution is a significant increase in the allowable arc eliminator currents. The sequential division of the interference current into individual semiconductor branches enables the conduction of fault currents much larger than the allowable conduction currents of a single thyristor, usually given in catalogs for a conduction time of $10 \mathrm{~ms}$. An additional advantage of arc eliminator is short-circuit current commutation in MSAE branches without arc and shortening the time of thermal effects' interaction in the protected circuit.

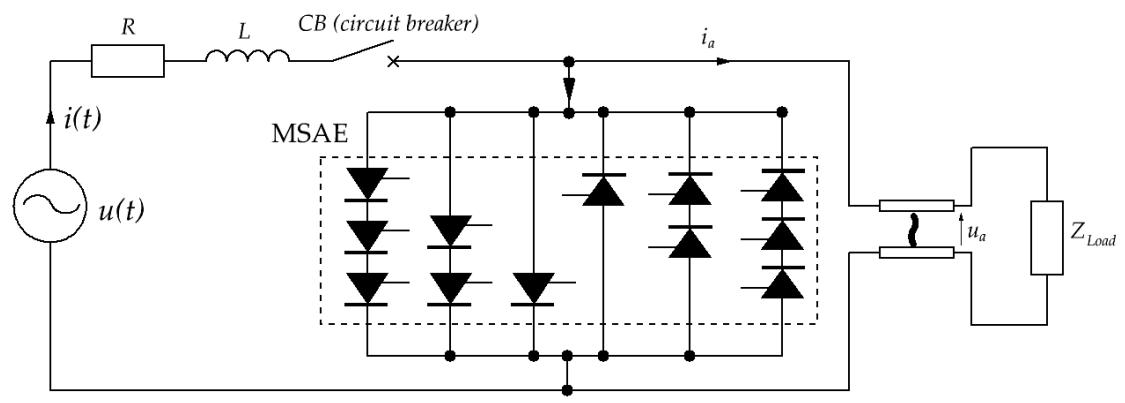

(a)

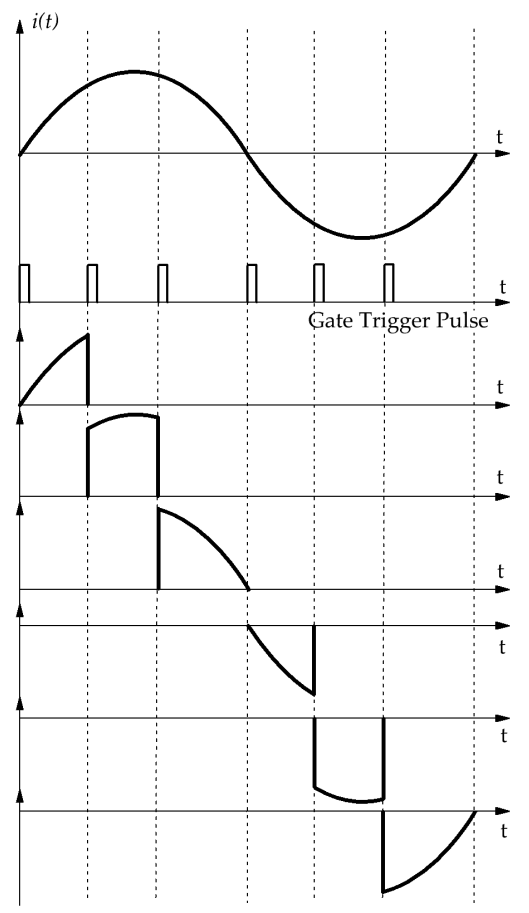

(b)

Figure 3. Multi-sectional structure of thyristors and operation of the MSAE: (a) Electrical scheme for an AC circuit with arc and MSAE made by the thyristors, (b) an example of sequential taking over current by shunting paths in the order in which thyristors are triggered. 
The voltage balance in the circuit with the arc can be determined from the equation:

$$
u(t)=R \cdot i_{a}+L \cdot \frac{d i_{a}}{d t}+u_{a}
$$

where $R$ is a circuit equivalent resistance, $L$ is a circuit equivalent inductance, $u_{a}$ is the instantaneous value of the arc voltage, and $i_{a}$ is the instantaneous value of arc current.

When an emergency arc occurs, the current through the $Z_{L O A D}$ working load is usually negligible. The energy supplied to the arc from the supplying electric circuit can be determined from the Equation (5) after multiplying both sides by the formula $i_{a} d t$ :

$$
u_{a} \cdot i_{a} d t=\left(u(t) \cdot i_{a}-i_{a}^{2} \cdot R\right) d t-L \cdot i_{a} d i_{a}
$$

Integrating Equation (6) within the arc burning time $\left(t_{1}\right.$-arc ignition moment, $t_{2}$-arc extinguisher moment), we will obtain the formula for the energy supplied to the arc:

$$
E=\int_{t_{1}}^{t_{2}} u_{a} \cdot i_{a} \cdot d t=\int_{t_{1}}^{t_{2}} q_{a}(t) \cdot d t
$$

where the variables are instantaneous values of arc voltage $u_{a}$, arc current $i_{a}$, and power consumed by the arc $q_{a}$.

The instantaneous value of the power $q_{a}$ is calculated from the dependence:

$$
q_{a}(t)=u_{a} \cdot i_{a}
$$

The observed actions and effects of a burning arc depend on the value of the current and the duration of the arc fault, as well as on the possibility and speed to move of the electric arc. Hence, one of the important methods of limiting the effects of emergency short circuits is shortening the short-circuit duration. Estimation of the basic energy parameters of the emergency arc during the arc fault ta enables the assessment of the hazards risk category, presented in Section 2.

\section{Gas Pressure in a Hermetic Casing with an Existing Emergency Arc}

The pressure rise inside the switchboard is primarily a function of the energy $e(t)$ taken from the network by the arc and converted into heat. The presence of apparatus and equipment near the electric arc, on the other hand, slightly reduces the temperature and pressure inside the covers of switchgear compartments. The following part of the paper presents an assessment of the impact of arc faults on the pressure increase in sealed casings, not equipped with safety flaps, but with floating membranes in the event of a sudden pressure increase inside the switchgear compartments (electrical junction box). The authors also attempted to verify the measured pressure increases about the calculated increases. The course of the pressure increase $\Delta p(t)$ in a tight, thermally insulated casing in which the free arc burns and all its energy $e(t)$ (in the form of heat) is evenly transferred to the surrounding air (in the form of heat), it is possible to calculate from the formula [32,33]:

$$
\Delta p(t)=k_{t} \cdot \frac{K-1}{V_{g}} \cdot E_{a}(t)
$$

where $k_{t}$ is a heat transfer coefficient (value calculated experimentally [32] for copper electrodes $\mathrm{Cu}-\mathrm{Cu} k_{t}=0.48$, for Al-Al $k_{t}=0.63$, and for Fe-Fe $\left.k_{t}=0.36\right), V_{g}$ is a net gas volume inside sealed electrical switchboard $\left(\mathrm{m}^{3}\right), K$ is adiabatic exponent (value read from the adiabatic diagram of selected gases) -For air it is $K=1.088$ [32], and $E_{a}$ is electric arc energy [J]. 


\section{Emergency Arc Which Burns on Copper Electrodes}

The experiment was carried out in the arrangement shown in Figure 3 for copper measuring electrodes with a diameter of $\varphi=2.21 \mathrm{~mm}\left(4 \mathrm{~mm}^{2}\right.$ wires). The system is powered by alternating voltage with an effective value of $230 \mathrm{~V}$. For safety reasons, the amplitude of the current in the circuit shown in Figure 3 has been limited to $1300 \mathrm{~A}$. The first stage of the tests was performed in a short-circuit electrical circuit with an inactive arc eliminator (MSAE OFF). The protection of the tested system is the circuit breaker CB (main switch).

The ignition of the electric arc and its subsequent effects were recorded with a Chronos 1.4 high-speed camera (Kron Technologies Inc., Burnaby, BC, Canada). The device is a 1.4 gigapixel-per-second handheld high-speed camera. It records $1280 \times 1024$ video at $1057 \mathrm{fps}$ and can record at up to 38,565 fps at a lower resolution. Such a large number of frames allows you to analyze the previously recorded electric arc explosion with an accuracy of $26 \mu \mathrm{s}$ for each photo. This gives great cognitive opportunities during research on the effectiveness of MSAE. Parameters of the high-speed Chronos 1.4 camera are listed in the Table 4.

Table 4. Parameters of a Chronos 1.4 high-speed camera (Adapted form [33]). Reproduced from 33], Krontech: 2018.

\begin{tabular}{cc}
\hline Parameters & Values \\
\hline $\begin{array}{c}\text { Color camera imaging } \\
\text { Camera memory }\end{array}$ & from $1280 \times 10241057 \mathrm{fps}$ to $336 \times 9638.565 \mathrm{fps}$ \\
Lens mount & $8 \mathrm{~GB}$ \\
Camera IR Filter & CS mount, C mount with the included adapter \\
Camera display & $650 \mathrm{~nm}, 18 \times 18 \times 1.1 \mathrm{~mm}$ \\
Video formats & $500 \times 480$ capacitive touchscreen \\
& H.264 industry-standard mp4 files at bitrates up to $60 \mathrm{Mbps}$ \\
cinemaDNG Raw Standard Adobe & speed $1.4 \mathrm{Gpx} / \mathrm{s}-\begin{array}{c}\text { Full throughput down to } 336 \text { pixel image width } \\
\text { dimensions } 8.45 \times 6.76 \mathrm{~mm} \\
\text { pixel pitch } 6.6 \mu \mathrm{m}\end{array}$ \\
Image sensor & shutter electronic global shutter, $1 / \mathrm{fps}$ to $1 \mu \mathrm{ss}(1 / 1,000,000 \mathrm{~s})$ \\
\hline
\end{tabular}

The waveforms recorded in the tested circuit are shown in Figure 4. In the moments $t_{1}=0 \mathrm{~ms}$ and $t_{6}=7.1 \mathrm{~ms}$, the first and second ignition of the electric arc takes place successively. The disturbance related to the electric arc ends at time $t_{8}=15.5 \mathrm{~ms}$. The total burning time of the electric arc for both half-waves of the flowing current was $t=13.8 \mathrm{~ms}$. The recorded waveforms in Figure 4 present in turn:

- $\quad$ Figure 4 a voltage waveform $u_{\text {power }}=f(t)$, voltage on the arc $u_{a}=f(t)$ and current in the branch with the arc $i_{a}=f(t)$,

- $\quad$ Figure $4 \mathrm{~b}$ the course of the measured pressure $p_{a}=f(t)$ inside the electrical box in which the arc disturbance occurred and the design pressure value (9) $p_{o b l}=f(t)$ for the installation electrical box in which there was no opening, and the arc burns during two half-waves of flowing electric current,

- Figure $4 \mathrm{c}$ waveforms of the calculated values of the power (8) consumed by the arc from the power network $q_{a}=f(t)$ and the energy (7) released in the $\operatorname{arc} e_{a}=f(t)$. 


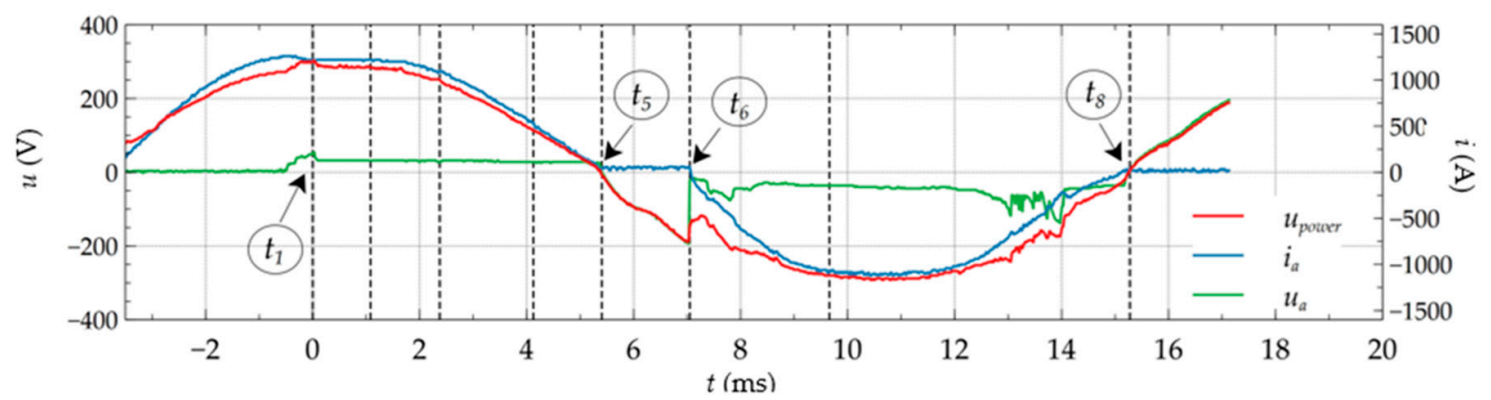

(a)

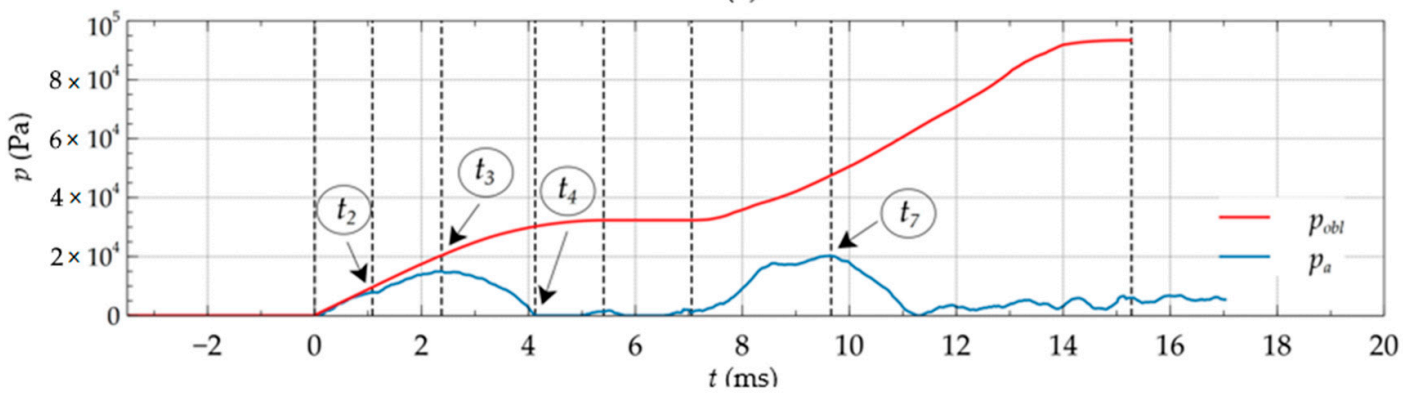

(b)

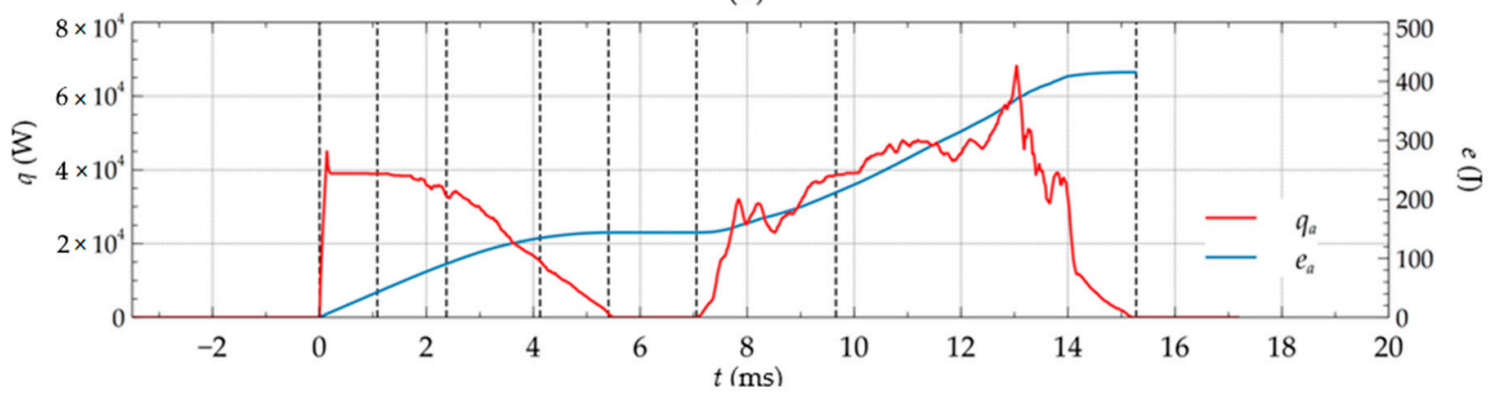

(c)

Figure 4. Waveforms as a function of the arc fault duration: (a) supply voltage $u_{\text {power }}$, arc voltage $u_{a}$ and current in the arc branch $i_{a} ;(\mathbf{b})$ measured and calculated pressure $p_{a}$ and $p_{o b l}$ inside the junction box casing; (c) power consumption by the arc $q_{a}$, and energy released on the arc $e_{a}$ as a function of the duration of the arc fault. Points $t_{1}-t_{8}$ correspond to the successive photographic images a-h presented in Figure 5.

For the waveforms presented in Figure 4, several characteristic points were determined. For the same points using a Chronos 1.4 high-speed camera recorded images shown in Figure 5. The interpretation of the individual points is as follows:

(1) Figures $4 \mathrm{a}$ and $5 \mathrm{a}-$ At the moment $t_{1}=0 \mathrm{~ms}$ inside the electrical junction box, the first electric arc ignition takes place. In the photo captured with a fast camera, a flash of an electric arc can be seen through a small viewfinder located on the side of the housing,

(2) Figures $4 \mathrm{~b}$ and $5 \mathrm{~b}-$ When $t_{2}=1.15 \mathrm{~ms}$ the junction box is opened and the gas pressure inside the installation box is slightly reduced. On the recorded pressure oscillogram, the opening moment of the electrical junction box is visible in the form of a recess in the characteristic. For the same time moment, the camera registered a visible opening of the electric junction box by lifting one of the edges of the installation box lid, which is resiliently attached to the housing catches,

(3) Figures $4 \mathrm{~b}$ and $5 \mathrm{c}$-At the time $t_{3}=2.3 \mathrm{~ms}$ the measured pressure reaches its local maximum, and in the next step it starts to decrease its value, which suggests the process of unsealing the electrical junction box,

(4) Figures $4 \mathrm{~b}$ and $5 \mathrm{~d}$-At the time $t_{4}=4.1 \mathrm{~ms}$ the pressure reduces its value to the value of the pressure before ignition of the electric arc. The burning electric arc inside the electrical junction box and the hot particles of the electrode material escaping outside, 
visible in the photo, prove a significant opened of the casing and a strong, erosive effect of the arc inside it,

(5) Figures $4 \mathrm{a}$ and $5 \mathrm{e}-$ At the moment $t_{5}=5.4 \mathrm{~ms}$, the zero-crossing of the electric current causing the extinguishing of the first electric arc (in Figure 5e it is revealed by the weakening of the glow inside the box),

(6) Figure $4 \mathrm{a}, \mathrm{b}$ and Figure $5 \mathrm{f}-$ At the time $t_{6}=7.1 \mathrm{~ms}$ the electric arc is re-ignited, and the measured pressure inside the installation box increases. The photo captured with a fast camera shows the moment of elastic closing of the installation box cover and burning hot particles of electrode material thrown outside, resulting from the previous ignition of the electric arc,

(7) Figures $4 \mathrm{~b}$ and $5 \mathrm{~g}$-At the time $t_{7}=9.6 \mathrm{~ms}$ the measured pressure locally reaches the next maximum (for the second ignition of the arc). The photo for the same time moment shows the flap of the installation box opening again and the hot copper drops (electrode material) escaping outside,

(8) Figures $4 \mathrm{a}$ and $5 \mathrm{~h}-$ At the moment $t_{8}=15.3 \mathrm{~ms}$, the electric arc is finally extinguished. The lid of the electric junction box closed by the elasticity of fastenings, as well as the heated internal elements and the remnants of the hot loss of electrodes inside the box, cause a slight increase in pressure, which can be observed on the recorded oscillogram (Figure $4 \mathrm{~b}$ ). Despite the arc extinguishing and the practically closed switchgear, the camera registered incandescent material that had managed to escape outside the electrical junction box.

Full photographic recording of the effects of emergency arc ignition, shown in Figure 5, is attached to this paper in the form of a time-lapse movie [34]. It shows the recorded film frames just before the ignition of the electric arc, through the ignition of the first and second arcs, and its end falls on the extinction of the remaining incandescent material losses from the measuring electrodes.

The evaluation of the measured and calculated pressure changes in the volume of the electrical junction box with the analyzed emergency arc can be performed based on the waveforms shown in Figure $4 \mathrm{~b}$. At the time $t_{1}=0 \mathrm{~ms}$, the electric arc is ignited for the flow of a positive current half-wave. In the photo recorded with a fast camera (Figure 5a), a flash of an electric arc inside the installation box can be seen through a small viewfinder located on the side of the electrical junction box. In the time from $t_{1}=0 \mathrm{~ms}$ to $t_{2}=1.15 \mathrm{~ms}$, the pressure inside the closed junction box, due to the burning electric arc, reaches a critical value, sufficient to open the installation cover of the electrical box. Shortly after the casing is opened, the measured pressure drops slightly—Figure $4 \mathrm{~b}$. 


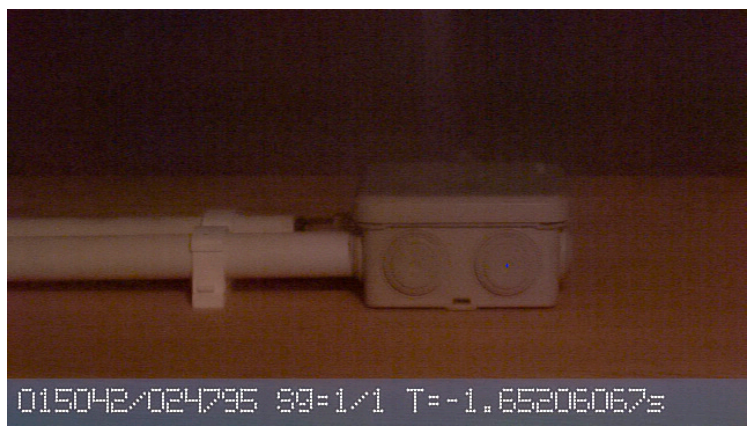

(a)

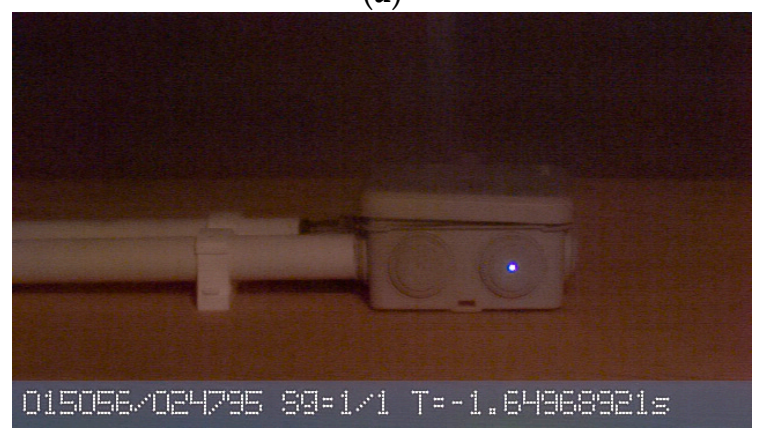

(c)

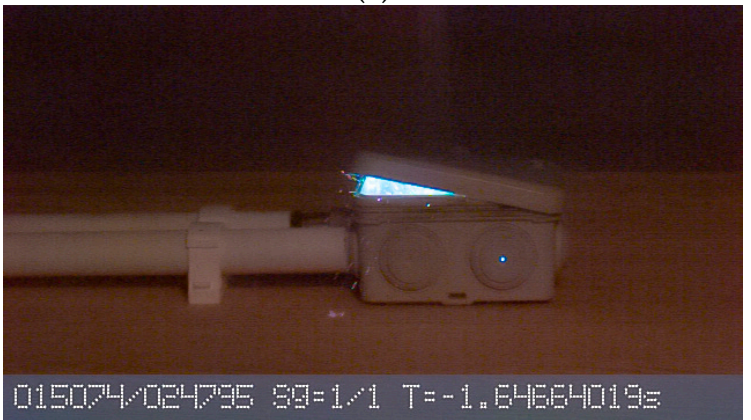

(e)

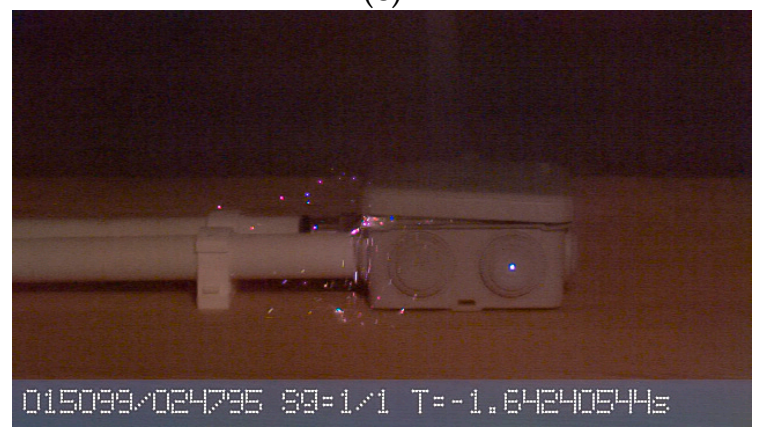

(g)

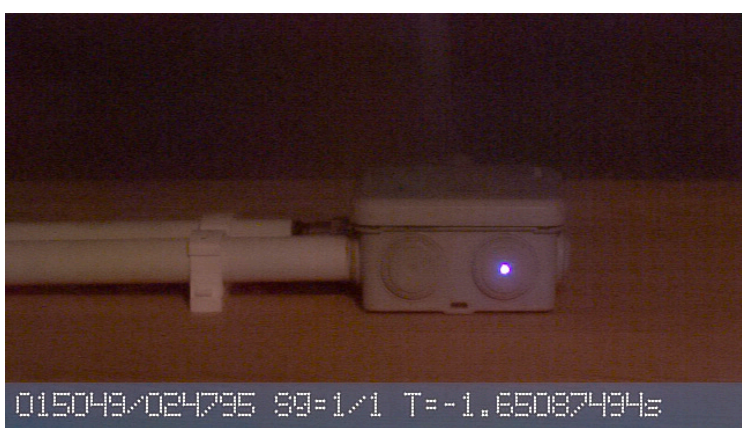

(b)

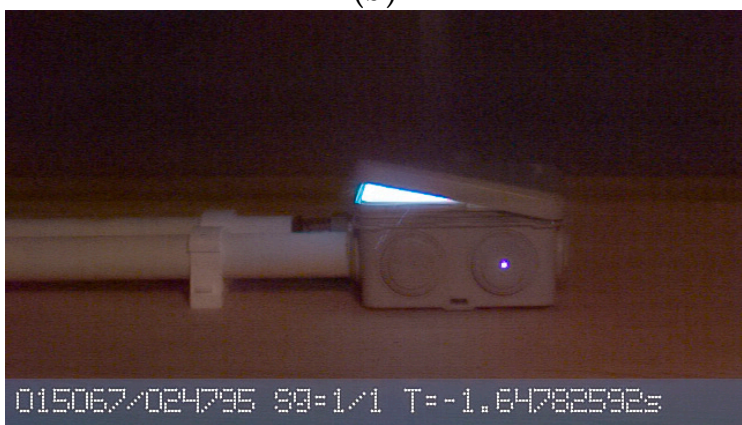

(d)

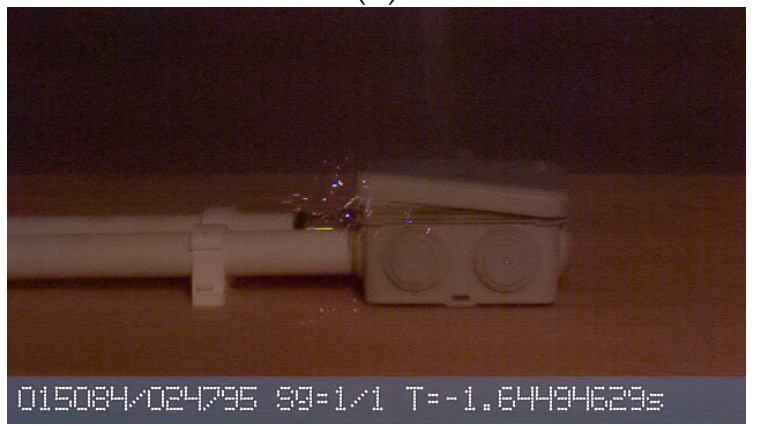

(f)

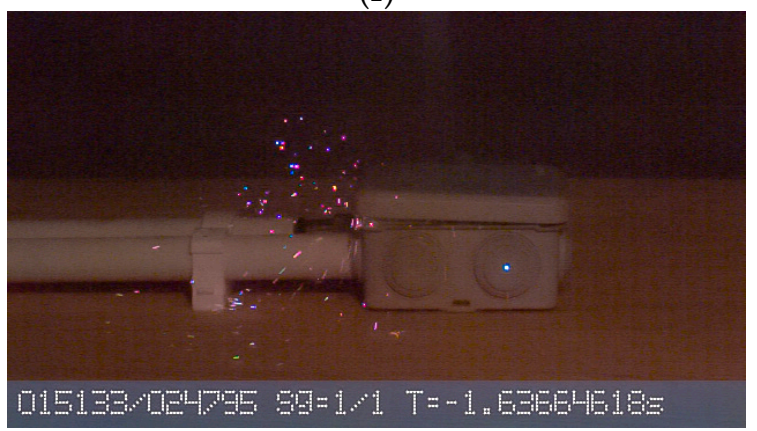

(h)

Figure 5. Photographic registration of the effects of the emergency arc in the electrical junction box (a) $t_{1}=0 \mathrm{~ms}$ electric arc ignition; (b) $t_{2}=1.15 \mathrm{~ms}$ switchgear opened; (c) $t_{3}=2.3 \mathrm{~ms}$ pressure maximum for the first period time of arc ignition; (d) $t_{4}$ $=4.1 \mathrm{~ms}$ the pressure reduces to that before the ignition of the electric arc; (e) $t_{5}=5.4 \mathrm{~ms}$ start of electric arc extinguishing; (f) $t_{6}=7.1 \mathrm{~ms}$ electric arc re-ignition; $(\mathbf{g}) t_{7}=9.6 \mathrm{~ms}$ maximum pressure in the second period, the arc is burning; (h) $t_{8}=15.3$ ms final electric arc extinguishing $\left(I_{m}=1300 \mathrm{~A}, \mathrm{U}=230 \mathrm{~V}, \mathrm{Cu}-\mathrm{Cu}\right.$ electrodes $)$.

Since the instantaneous arc power is never negative, negative pressure gains can't occur. It follows that at time $t_{2}$ there was an elastic opening of the cover closing the junction box and the pressure drop through the created gap. This conclusion is also confirmed by the image recorded with a fast camera. The pressure built up inside, calculated according to Equation (9) at the moment of unsealing the can, is $9.75 \mathrm{kPa}$. The measured pressure value 
for the same time instant reaches the value of $7.9 \mathrm{kPa}$. The increase in the measured pressure $\Delta p_{a}$ in the initial phase of the arc disturbance until the electrical junction box is opened largely coincides with the increases in the calculated pressure curve $\Delta p_{o b l}$. The conclusion is that knowing the arc energy characteristics $e_{a}(t)$ and knowing that the pressure increase is primarily a function of this energy, it is possible to determine the pressure curve inside the sealed switchgear with high accuracy. The course of the pressure increased calculated $p_{o b l}(t)$ and measured $p_{a}(t)$ cease to coincide over time from the moment of opening the switchgear. A further attempt to compare both values does not give reliable results. However, further calculation of the increment of $p_{o b l}(t)$ for the subsequent ignition of the arc allows estimating the value of the pressure in the tightly closed electrical junction box. The lack of ventilation flaps or safety membranes causes a further increase in the overpressure value as a function of the arc energy. In Figure $4 b$, the calculated pressure after $t_{7}=15.3 \mathrm{~ms}$, corresponding to the total arc burning time, could reach $94 \mathrm{kPa}$ inside the junction box. After $t_{3}=2.3 \mathrm{~ms}$, the gas pressure inside the junction box reaches a maximum of $15 \mathrm{kPa}$. The energy supplied to the arc is then $88 \mathrm{~J}$, and the power input from the power network needed to sustain the burning arc is $35.5 \mathrm{~kW}$. The lid closing the junction box is opened and from that moment the primary and secondary products of the emergency arc in the form of metal vapors from electrode erosion, hot and toxic gases, smoke, etc. begin to escape into the environment from its interior. The described condition is well illustrated in Figure 5 and the time-lapse movie is recorded with a fast-speed camera [33]. At the time $t_{4}=4.1 \mathrm{~ms}$, the measured pressure reaches a value close to the initial (atmospheric) pressure, which is related to the considerable opening of the installation box cover-Figure $5 \mathrm{c}$. In general, this situation continues until the current crosses zero (or is turned off). In the previously analyzed case, after the arc was extinguished, the can lid was closed, causing the apparent sealing again. The favorable thermal conditions and the small distance between the electrodes cause another arc ignition, this time for the negative half-wave of the supply voltage. At the time $t_{6}=7.1 \mathrm{~ms}$, the electric arc re-ignites, and the pressure of gases inside the closed installation box increase further. The second ignition of the arc and high temperature (next heating after the previously existing first electric arc) cause an increase in pressure at the time $t_{7}$ $=9.6 \mathrm{~ms}$, up to $20.3 \mathrm{kPa}$, arc power energy up to $210 \mathrm{~J}$, and power input from the power network up to $38.2 \mathrm{~kW}$. In the next milliseconds of burning electric arc, the pressure of gases inside the junction box begins to decrease its value due to the subsequent opening of its cover. At $t_{8}=15.3 \mathrm{~ms}$, when the arc is extinguished, the pressure inside the switchgear decreases and fluctuates within $5 \mathrm{kPa}$. The high temperature inside the arc source housing, the flying in the air residual material loss from the electrodes and the re-closed installation box lid maintains the overpressure inside the box for some time.

Figure 6 shows the interior view of the electrical junction box and the effects of ignition of an electric arc burning for the time of $8.9 \mathrm{~ms}$. It can be seen that even for such a short arc time, there is intense destruction of the electrodes and elements inside the electrical box. This is especially dangerous from the point of view of fire protection. Most of the part energy generated in the arc can initiate ignition of flammable elements in the vicinity of the electric arc. 


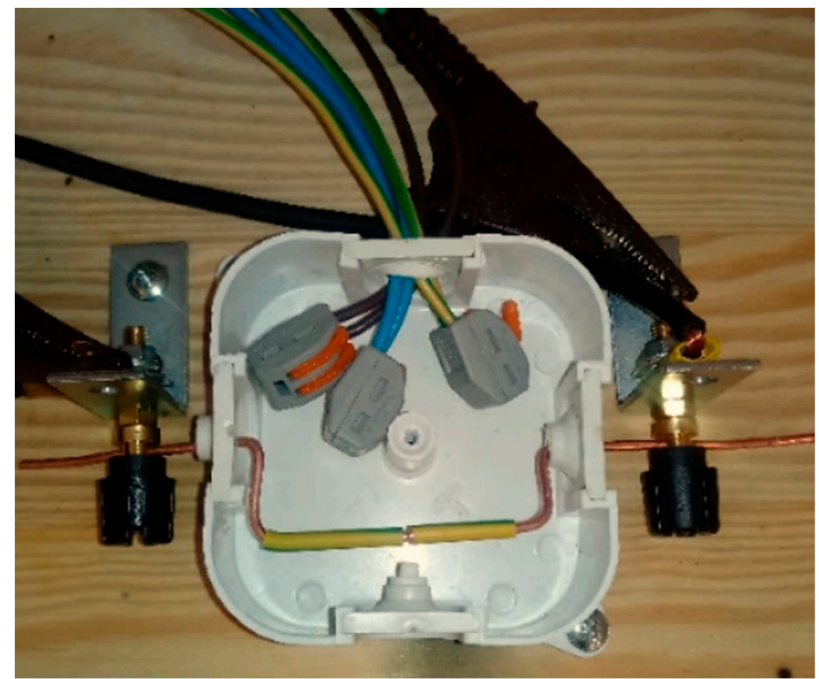

(a)

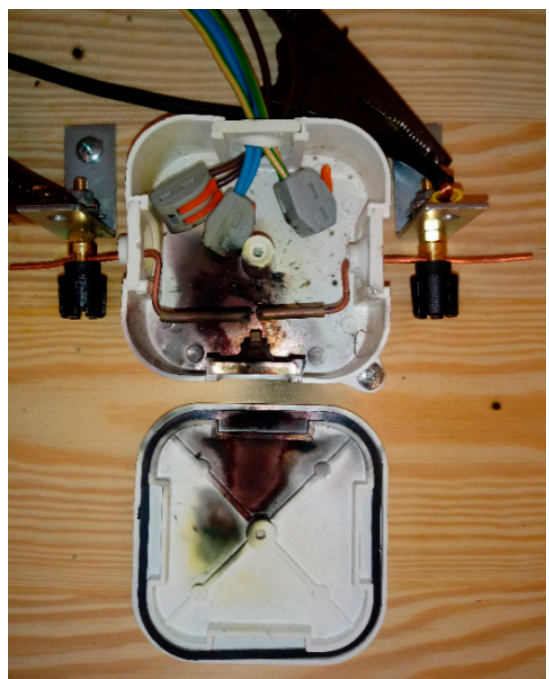

(b)

Figure 6. View of the inside of the electrical junction box before (a) and after (b) the arc fault test; supply voltage $230 \mathrm{~V}$; the arc current $1000 \mathrm{~A}$; the electric arc duration time $8.9 \mathrm{~ms}$.

The selected photos shown in Figure 7 were recorded during the ignition of the electric arc in the unsealed casing of the electrical junction box. The deliberate removal of the rubber insulating membranes made it possible to observe the direction of travel of the products of the electric arc explosion. The emission of hot gases that travel along the conductors can damage the insulation and further ignite the arc inside the electrical bushings. Despite the possible exit route for gases through the passages on its sidewall, it was found that the large and rapid increase in pressure inside the installation box still caused the arc source housing to unseal and the gases to be emitted outside.

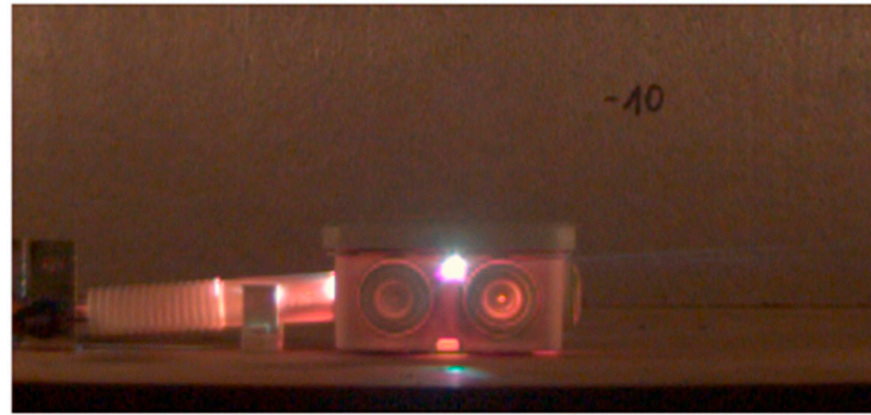

(a)

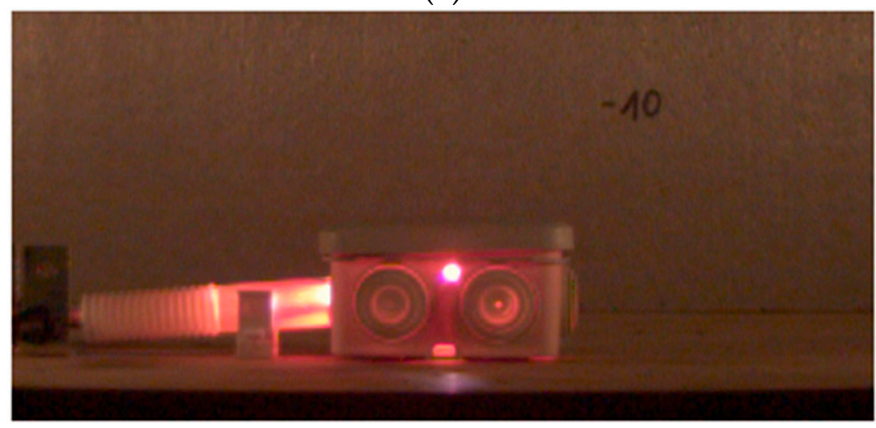

(c)

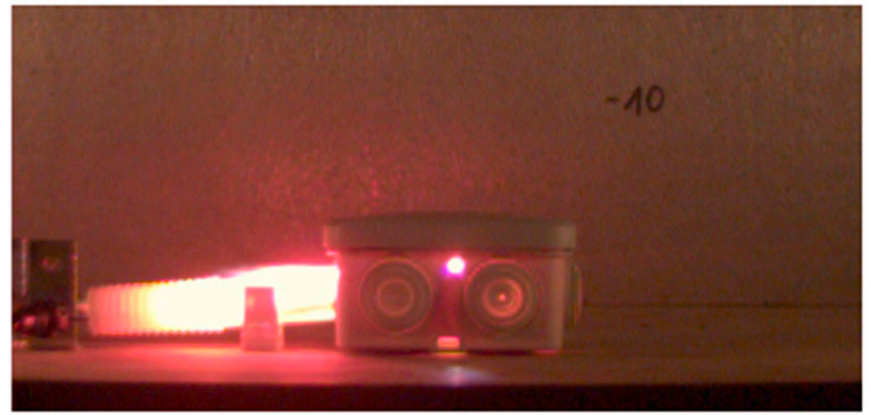

(b)

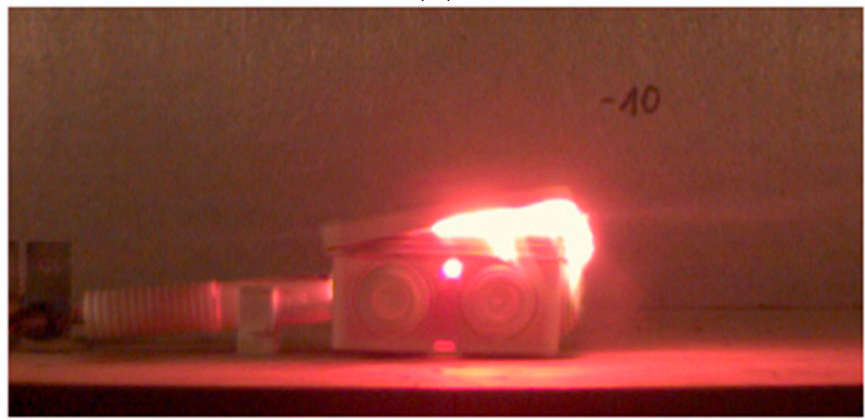

(d)

Figure 7. Evolution and product release of plasma and emergency arc products within the elements of a non-hermetic installation junction box (a) $t=0.5 \mathrm{~ms}$; (b) $t=1.5 \mathrm{~ms}$; (c) $t=2.5 \mathrm{~ms}$; (d) $t=3.5 \mathrm{~ms}\left(I_{m}=1250 \mathrm{~A}, U=400 \mathrm{~V}\right.$, Cu-Cu electrodes). 
Figure 8 shows an arc current and voltage oscillogram for three half-waves of the arc disturbance. The waveforms were recorded in the arrangement of Figure 3 without MSAE. The receiver is supplied with a phase-to-phase voltage of $400 \mathrm{~V}$, and the electrodes of the arc source are made of aluminum wires with a diameter of $\varphi=2.38 \mathrm{~mm}$.

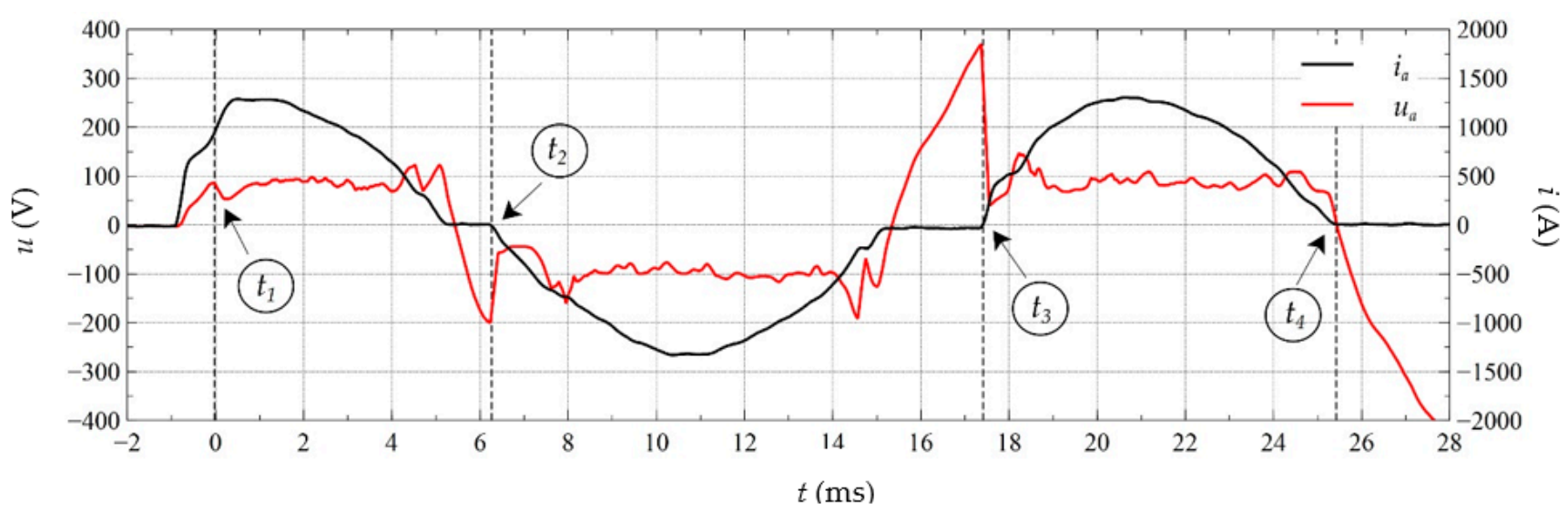

Figure 8. The waveform of the arc current $i_{a}(t)$ and the arc voltage $u_{a}(t)$ for three half-waves of the arc disturbance).

Four characteristic points are marked on the waveforms in Figure 8:

- first ignition of the electric arc $t_{1}=0 \mathrm{~ms}$,

- second ignition of the electric arc $t_{2}=6.25 \mathrm{~ms}$,

- third ignition of the electric arc $t_{3}=17.4 \mathrm{~ms}$,

- $\quad$ end of arc fault $t_{4}=25.4 \mathrm{~ms}$.

The arc duration time is $t_{a}=25.4 \mathrm{~ms}$.

The photos presented in Figure 9 show the image of the arc at the time moments of the first, second, and third ignition of the electric arc. For an interfacial short circuit and much greater arc energy, the increase in pressure inside a closed junction box enclosure is capable of tearing off and ejecting the lid of the enclosure for several tens of centimeters. This is accompanied by the creation of a deafening acoustic wave, a rapid temperature rise, and the ejection into the environment of the primary and secondary products of the emergency arc in the form of metal vapors and droplets from the erosion of aluminum electrodes.

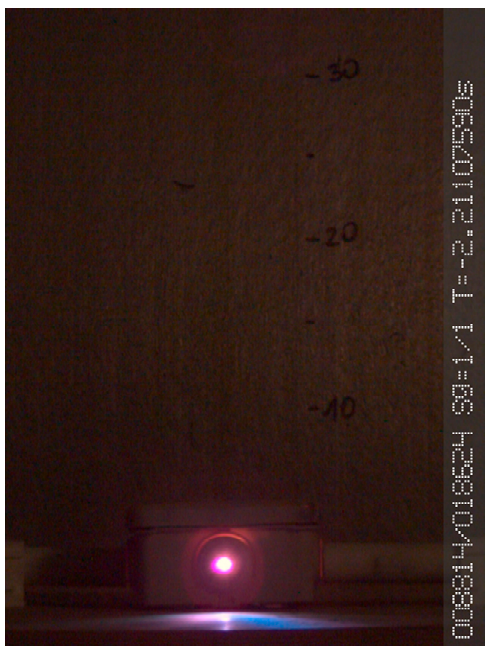

(a)

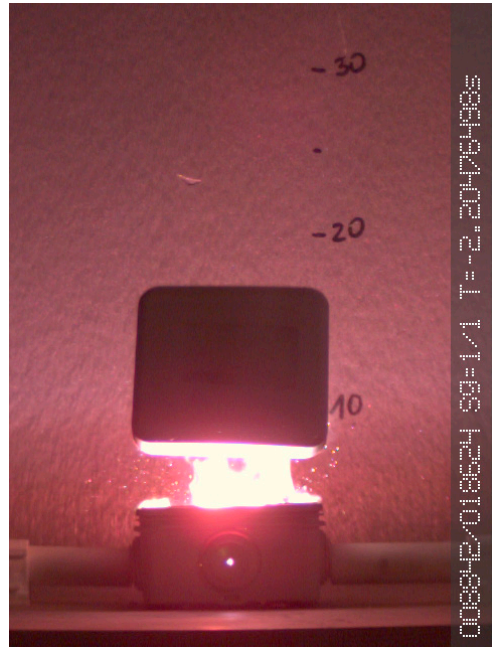

(b)

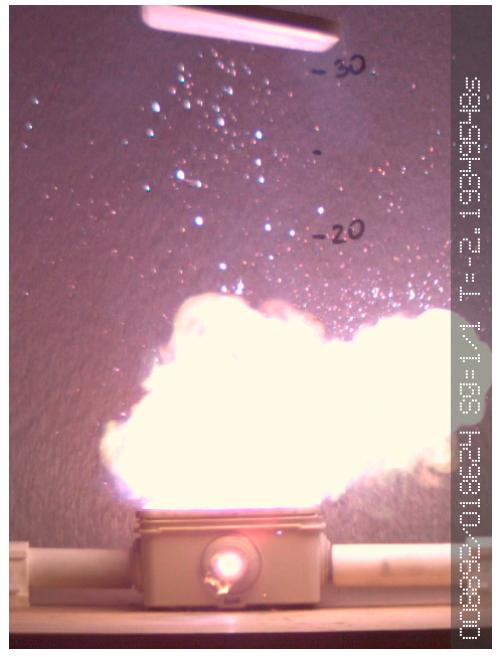

(c)

Figure 9. Development of the arc discharge for three successive ignitions of the electric arc: (a) first ignition of the electric arc $t_{1}=0 \mathrm{~ms}$, (b) second ignition of the electric arc $t_{2}=6.25 \mathrm{~ms}$, (c) third ignition of the electric arc $t_{3}=17.4 \mathrm{~ms}\left(I_{\mathrm{m}}=1250 \mathrm{~A}\right.$, $U=400 \mathrm{~V}, \mathrm{Al}-\mathrm{Al}$ electrodes). 
Figure 10 shows a sequence of selected frames of film recording for an arc burning between electrodes made of aluminum. The time of the disappearance of the electric discharge $t_{4}=25.4 \mathrm{~ms}$ does not mean the end of the danger posed by the occurrence of the emergency arc. The exploding material from the electrodes poses a real danger of burns and fire even after $500 \mathrm{~ms}$ from the moment when the electric arc is extinguished, which is proved by the last frame of the presented recording, which shows still hot drops of aluminum. The height markers visible in the photos (clearly visible in Figure 10 at $t=20 \mathrm{~ms}$ ) were scaled in centimeters. In the registered frames of the video, it can be seen that the heated aluminum droplets float above the last marker located at a height of $30 \mathrm{~cm}$.
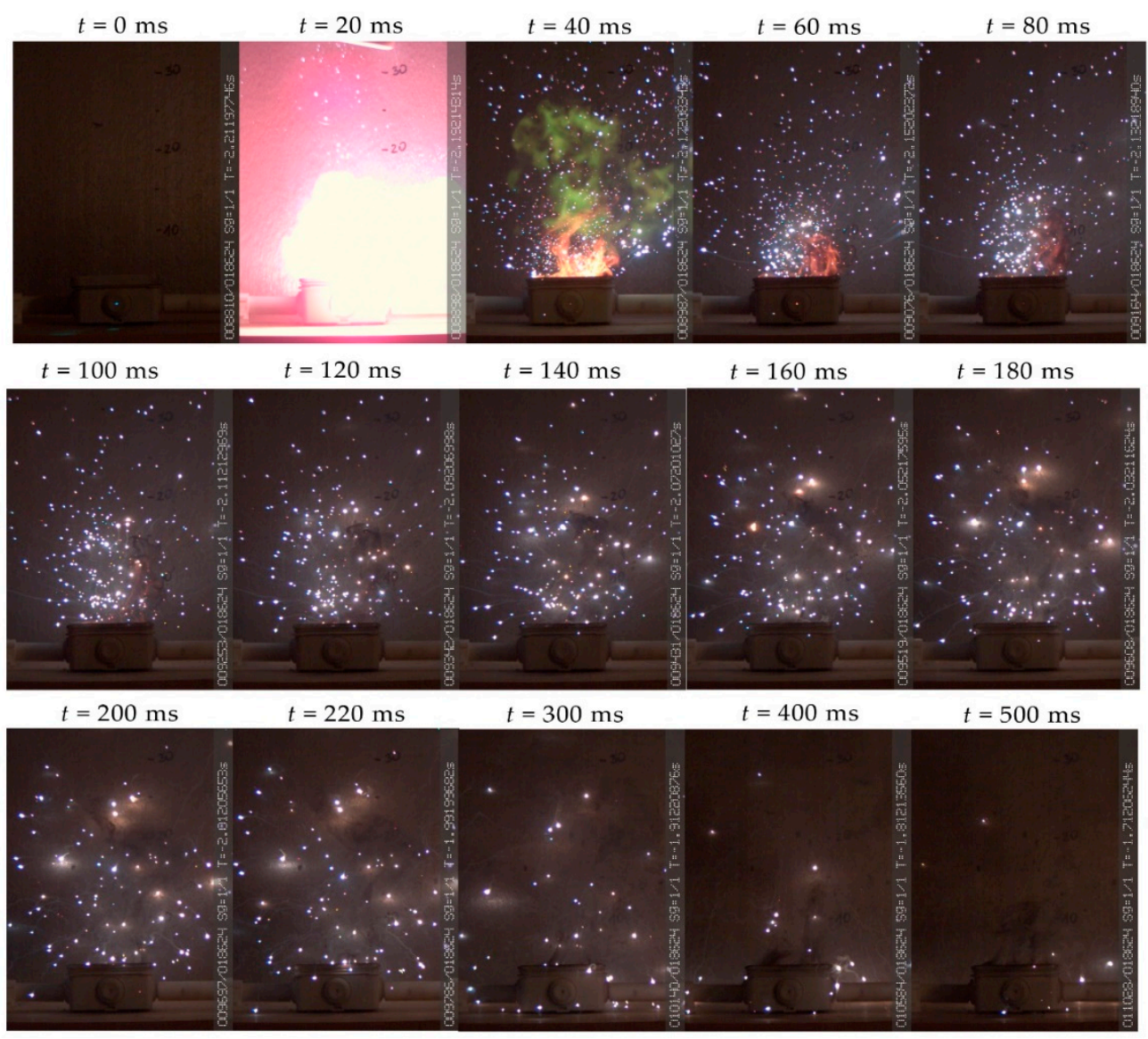

Figure 10. Selected frames of recording the effects of an emergency arc from its ignition to the almost complete extinction of the exploding, glowing remains of drops of electrode material $\left(I_{m}=1250 \mathrm{~A}\right.$, $U=400 \mathrm{~V}, \mathrm{Al}-\mathrm{Al}$ electrodes).

Full photographic recording of the effects of emergency arc ignition, shown in Figure 10, is attached to this article in the form of a time-lapse movie [35]. It shows the recorded frames of the film from the moment the arc ignited, through the subsequent ignitions of the arc, until the moment the remaining glowing loss of material from the aluminum electrodes expired.

The unsealing of the electrical junction box occurred $2.72 \mathrm{~ms}$ after the arc was ignited. The measured pressure value just before unsealing the casing was $48 \mathrm{kPa}$, the energy in the arc was $266 \mathrm{~J}$, and the power input from the power network was $85 \mathrm{~kW}$. If the housing had not been opened, the calculated value of pressure in the closed installation box, in the final phase of the arc, would have reached the enormous value of $310 \mathrm{kPa}$ at arc energy of $1750 \mathrm{~J}$. The use of the Chronos 1.4 high-speed camera made it possible to record the moment of unsealing of the electrical installation box. Figure 11a shows the moment just before it unseals. In the next photo from the film, Figure $11 \mathrm{~b}$, recorded after $0.225 \mathrm{~ms}$, one can see the initial unsealing of the junction box (lifting of the electrical box lid) and the arc glow up 
flash on the back wall of the arc source casing. This allows for accurate determination of the time of unsealing the housing.

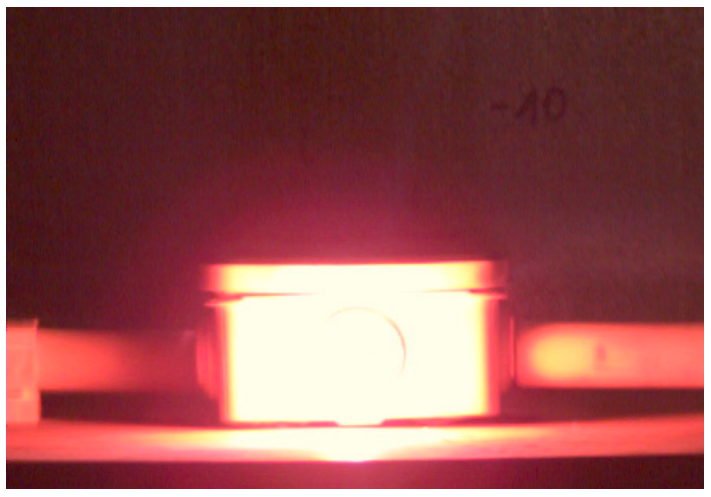

(a)

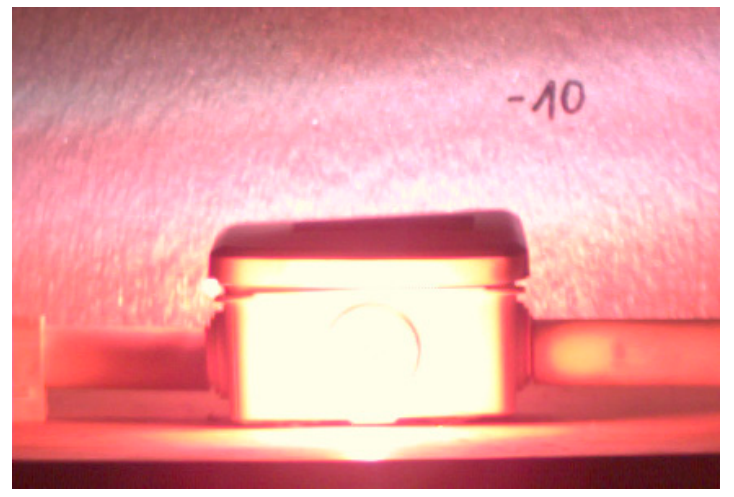

(b)

Figure 11. Subsequent frames from recording the behavior of the test object: (a) just before unsealing the electrical installation box, (b) immediately after opening the electrical installation box; $225 \mu$ s time interval.

\section{Testing the Effect of the Emergency Arc in a System with an Arc Eliminator}

The experiment was carried out in the system shown in Figure 3 for copper measuring electrodes with a diameter of $\varphi=2.21 \mathrm{~mm}\left(4 \mathrm{~mm}^{2}\right.$ wire). The system is powered by phase voltage with an effective value of $230 \mathrm{~V}$. The current amplitude in the circuit from Figure 3 was limited (as in previous tests) to a value of $1300 \mathrm{~A}$. The tests were carried out to verify the effectiveness of reducing the effects of the emergency arc by using a thyristor multi-sectional arc eliminator (MSAE), the operation of which is presented in the work [25]. The waveforms in Figure 12 represent in turn:

(1) voltage waveform on the arc $u_{a}=f(t)$, current in the branch with the arc $i_{a}=f(t)$, the current flowing through the shunting system MSAE $i_{T}=f(t)$, and the arc flash detection pulse $i m p_{w y z}=f(t)$,

(2) the course of the measured pressure $p_{a}=f(t)$ inside the installation electrical box in which the arc fault occurred and the calculated pressure value $p_{o b l}=f(t)(9)$ for the arc duration,

(3) the course of the calculated value of the power (8) consumed by the arc from the power network $q_{a}=f(t)$ and the energy (8) released on the arc $e_{a}=f(t)$ calculated for the arc duration.

Analyzing the waveforms shown in Figure 12a, five-time characteristic points can be distinguished:

- at time $t_{1}=0 \mathrm{~ms}$ the electric arc is ignited,

- at time $t_{2}=0.05 \mathrm{~ms}$ the arc flash is detected and the thyristors of the MSAE are triggered,

- at time $t_{3}=0.69 \mathrm{~ms}$ full conduction is taken over by the shunt branch of MSAE,

- at the time $t_{4}=0.9 \mathrm{~ms}$ the electric arc is extinguished,

- at the time $t_{5}=1.2 \mathrm{~ms}$ the measured pressure locally reaches the first maximum.

During the flow of current in the circuit at the time $t_{1}=0 \mathrm{~ms}$, a disturbance in the form of ignition of the electric arc occurs. The flash detector placed close to the arc generates a pulse that triggers the thyristors of the MSAE system after only $0.05 \mathrm{~ms}$ (at time $\left.t_{2}\right)$. The time delay of the thyristor triggering system, resulting from the internal structure and the semiconductor elements used, causes that after $0.64 \mathrm{~ms}$ from the moment of flash detection, at $t_{3}=0.69 \mathrm{~ms}$, the shunting MSAE system begins to conduct. MSAE semiconductor elements take over the current flow from the branch affected by the arc fault. The complete absence of current in the arc-affected branch occurs $0.21 \mathrm{~ms}$ after the MSAE is triggered. 
The arc time $t_{a}=0.9 \mathrm{~ms}$ passes from the moment the arc appears until it is completely extinguished.

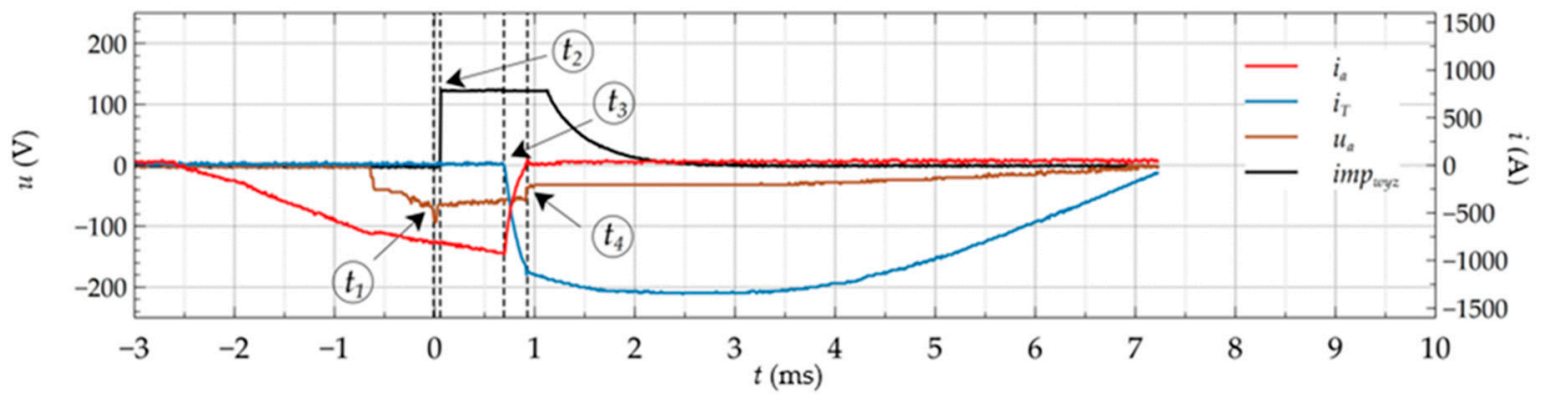

(a)

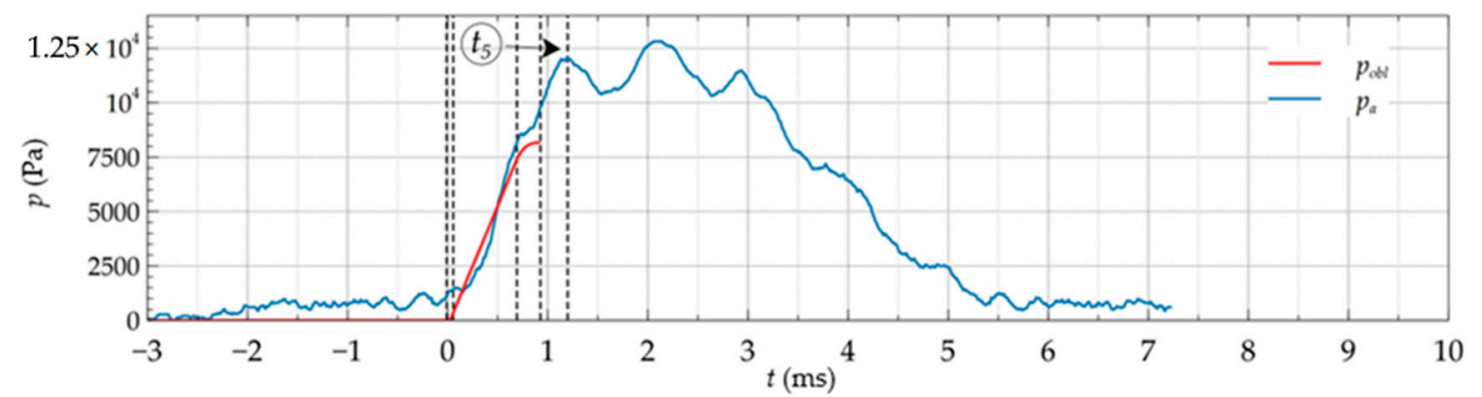

(b)

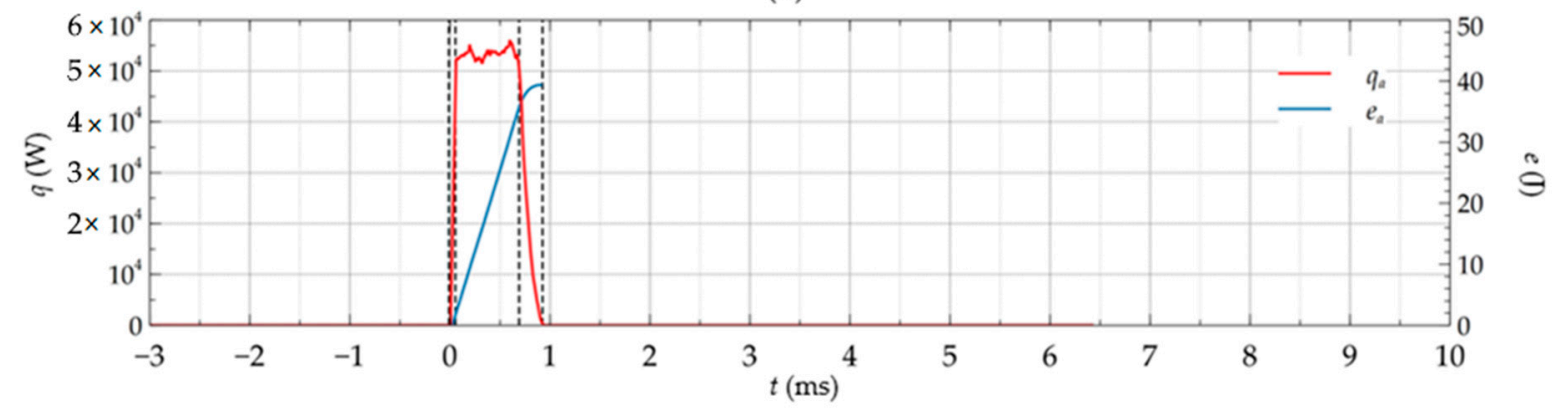

(c)

Figure 12. Waveforms as a function of the arc fault duration: (a) arc voltage $u_{a}$, current in the arc branch $i_{a}$, current in the MSAE $i_{T}$ branches, arc flash detection pulse $i m p_{w y z},(\mathbf{b})$ measured pressure pa and calculated $P_{o b l}$ inside the electrical junction box, (c) arc power $q_{a}$ and arc energy $e_{a}$ as a function of the arc disturbance duration.

The increase of the measured pressure $\Delta p_{a}$ inside the closed casing of the junction box in the time from the moment of arc ignition $\left(t_{1}=0 \mathrm{~ms}\right)$ to the complete taking over of the conduction by the bypass MSAE system $\left(t_{4}=0.9 \mathrm{~ms}\right)$ is collinear with the increase of the calculated pressure value $\Delta p_{o b l}$. When the conduction is fully taken over by the MSAE shunt, the measured pressure is $p_{a}=9.7 \mathrm{kPa}$, and the calculated pressure is $p_{o b l}=8.1 \mathrm{kPa}$. The calculated pressure $p_{o b l}$ reaches $8.1 \mathrm{kPa}$ and does not increase any further because the arc does not burn (the current in the arc branch does not flow, and thus the energy released in the arc is 0 ).

The short-term increase in pressure inside the electrical box while the arc is burning did not unseal it. The waveform presented in Figure $12 \mathrm{~b}$ shows that the measured value of pressure pa continues to increase and reaches its maximum at $12.5 \mathrm{kPa}$ despite the no longer burning electric arc. This increase may result from the heating of the air in the enclosure of the closed installation box, which is maintained by the heat dissipation of the heated copper arc electrodes, the walls of the enclosure, and the equipment. As a result, there was a slight open of the junction box, but it happened after the electric arc was extinguished. The power consumed from the mains, needed to sustain the burning arc, 
reaches the value of $55 \mathrm{~kW}$, and then when the MSAE is fully activated, it reduces its value to zero. The arc energy reaches its maximum at the level of $40 \mathrm{~J}$ and stops growing when MSAE is triggered because the arc does not burn.

The key frames of the disturbance recording in Figure 12 are shown in Figure 13. The tripping of MSAE significantly reduces the arc duration, which in turn reduces the arc energy and pressure inside the electrical box. No opening of the electrical box during arc ignition, shortening of the arc duration, reduction of arc energy causes:

- reduction of the loss of electrode material,

- limiting the temperature rise inside the switchgear,

- no emission of plasma, hot gases, smoke, and metal drops to the environment,

- no deafening sound wave.

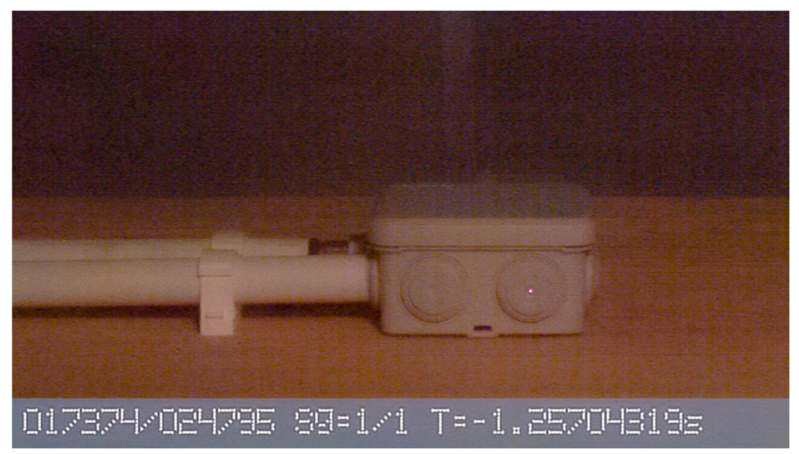

(a)

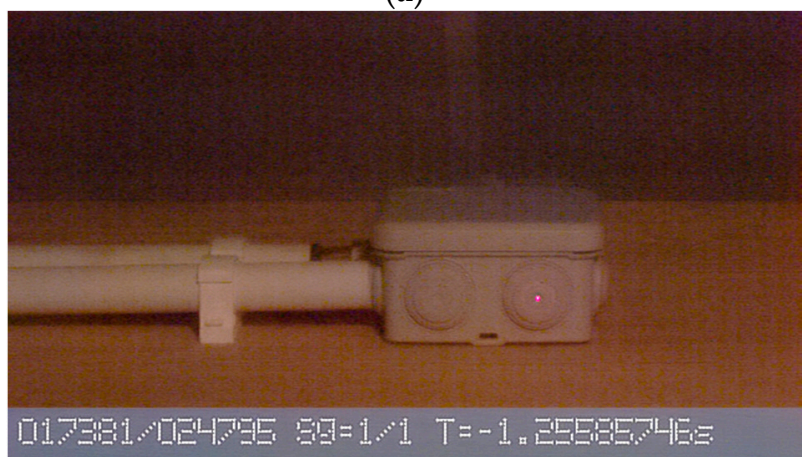

(c)

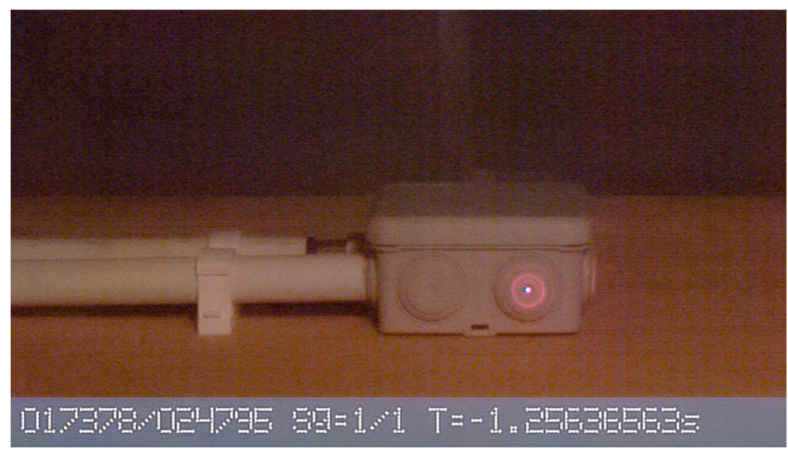

(b)

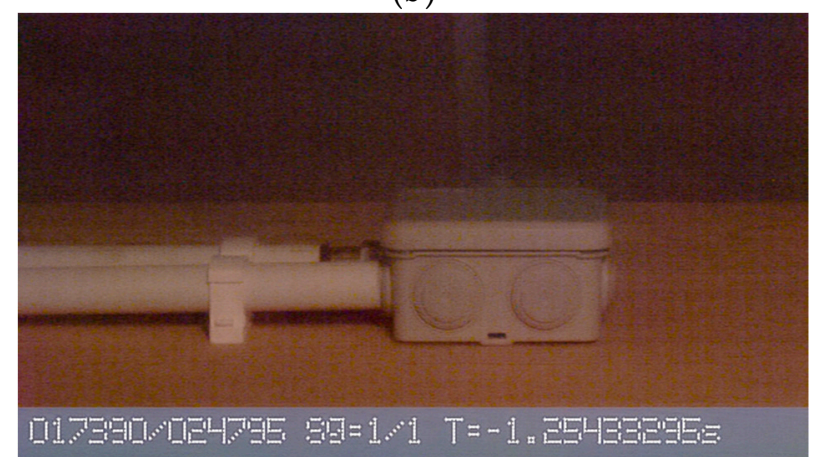

(d)

Figure 13. Images of the state of the installation box during an arc fault in a system equipped with an MSAE emergency arc eliminator: (a) $t_{1}=0 \mathrm{~ms}$ electrcial arc initiation phase, (b) $t_{3}=0.69 \mathrm{~ms}$ beginning of conduction through $\mathrm{MSAE},(\mathbf{c}) t_{4}=0.9$ ms full conduction by MSAE, (d) $t=2.65 \mathrm{~ms}$ electrcial arc extinction phase $\left(I_{m}=1300 \mathrm{~A}, \mathrm{U}=230 \mathrm{~V}\right.$, Cu-Cu electrodes).

The junction box status images from Figure 13 recorded during an arc fault in a system equipped with an MSAE arc eliminator show in turn:

- $\quad$ at the moment $t_{1}=0 \mathrm{~ms}$ the arc fault initiation phase,

- at the moment $t_{3}=0.69 \mathrm{~ms}$ start of electric arc extinguishing by activation of MSAE. The energy emitted in the arc reaches its maximum, and in the photo, you can see intense illumination inside the installation box. The analysis of the recorded photos after time $t_{3}$ (MSAE on) shows that the intensity of the "glow" inside the installation box decreases considerably,

- at the time $t_{4}=0.9 \mathrm{~ms}$, MSAE is fully conducted, which forces the electric arc to extinguish. The shining point visible in the photo is not the effect of a burning electric arc, but the remnants of an exploding fuse material made of copper wire,

- the photo taken at the time $t=2.65 \mathrm{~ms}$ from the moment of initiation of the electric arc was registered during the flow of the maximum value of the supply current. 
Full photographic recording of electric arc ignition in the system equipped with MSAE in Figure 13 is attached to this article in the form of a time-lapse movie [36]. It shows the recorded frames of the film from the moment of ignition of the electric arc, through the stage of MASE activation, to the complete extinction of the electric arc.

\section{Calculation of the Hazard Risk Category}

The effects of a burning arc depend on the value of the current and the duration of the arc disturbance. The arc burning time is directly related to the energy released in the electric arc. Reducing the arc fault time will reduce the arc energy and the amount of heat re-leased during arc burning. Reducing the arc fault time will also reduce the value of the electric current flowing in the arc circuit. The estimation of the basic energy parameters of the emergency arc enables to assess the degree of the hazard risk category, during the du-ration of the short circuit $t_{a}$.

On the basis of authors' experience, one of the most effective ways to reduce the effects of an electric arc flash is to reduce the arc burning time. In the work [25] and Section 7, the effectiveness of full MSAE activation within $0.9 \mathrm{~ms}$ from the appearance of the elec-tric arc was demonstrated. To calculate the hazard risk category, based on the Equations (1)-(3) caused by an electric arc according to IEEE 1584 [1,2,4,5], two variants based on actual measurement results were adopted. The first variant includes calculations and measurements for the facility without an MSAE system, which was presented in Section 6, the second one includes calculations for the MSAE protected system, which was presented in Section 7.

Assumptions for the conducted experiment:

- copper electrodes placed inside the installation electrical box,

- $\quad$ system supplied with $230 \mathrm{~V}$ single-phase voltage,

- $\quad$ arc current $I_{a}[\mathrm{kA}]$ (arcing current) read from the recorded waveforms,

- $\quad$ arc burning time $t_{a}=15.3 \mathrm{~ms}$ for a system without MSAE,

- $\quad$ arc burning time $t_{a}=0.9 \mathrm{~ms}$ when MSAE is activated,

- distance between parallel current paths in the analyzed circuit $G=3 \mathrm{~mm}$,

- distance of the person's body from the source of the arc D $=50 \mathrm{~mm}-$ We assume that the person is in direct contact with the installation box (e.g., by performing checking activities),

- $K_{1}$ coefficient equal to -0.555 when the analyzed device is closed in sealed switchgear and -0.792 when the arc burns in an open space (the switchgear is opened),

- $\quad$ the exponent of distance $x$ for an arc burning in an open space is 2 and 1.473 for an arc burning in a closed junction box.

Table 5 presents the results of calculations of the arc energy, fire zone, and hazard risk category for the experiment without MSAE (MSAE OFF) and in the system where MSAE was active (MSAE ON). The hazard risk category is directly related to the energy value of $E\left(\mathrm{~J} / \mathrm{cm}^{2}\right)$. In a situation where the facility is not MSAE equipped, the only way to reduce the risk is to increase the worker's distance from the source of the arc. The Arc Flash Hazard Assessment for the experiment presented in Section 6, assigned a category 1 to this disturbance.

Table 5. The results of calculating the arc energy, flash protection boundary, and hazard risk category for the experiment without MSAE (MSAE OFF) and in the system with MSAE (MSAE ON).

\begin{tabular}{ccccccc}
\hline $\begin{array}{c}\text { Type of } \\
\text { Work }\end{array}$ & $\boldsymbol{t}_{\boldsymbol{a}}(\mathrm{ms})$ & $E_{\boldsymbol{n}}\left(\mathrm{J} / \mathrm{cm}^{2}\right)$ & $E\left(\mathrm{~J} / \mathrm{cm}^{\mathbf{2}}\right)$ & $E\left(\mathbf{c a l} / \mathrm{cm}^{2}\right)$ & $D_{\boldsymbol{B}}(\mathbf{m m})$ & HRC \\
\hline MSAE OFF & 15.3 & 0.22 & 16.02 & 3.83 & 89.52 & 1 \\
MSAE ON & 0.09 & 0.38 & 0.43 & 0.10 & 9.45 & 0 \\
\hline
\end{tabular}

The designated hazard risk category 1 requires the use of personal protective equipment $[1,2,4,5]$ : 
- $\quad$ safety glasses,

- earplugs,

- protective helmet,

- helmet visor certified for $\mathrm{min} .4\left(\mathrm{cal} / \mathrm{cm}^{2}\right)$,

- leather safety shoes,

- leather gloves or leather gloves on electrical insulating gloves,

- underwear made of non-flammable materials,

- clothing (long trousers + long sleeve blouse or overalls) arc protection certified to min. $4\left(\mathrm{cal} / \mathrm{cm}^{2}\right)$.

The boundary of the arc damage zone calculated from the Equation (4) is $89.52 \mathrm{~mm}$. It means that a person within the assumed distance $\mathrm{D}=50 \mathrm{~mm}$ is exposed to the direct effects of an electric arc.

Arc Flash Hazard Assessment in a system with an arc disturbance equipped with an MSAE device and described in Section 7, has shown that it falls under hazard category 0 . The use of the MSAE arc eliminator shortens the arc time and thus reduces the arc flash hazard and significantly shortens the arc flash zone boundary to $9.45 \mathrm{~mm}$. The safe operating distance of the device has increased almost tenfold, and the assumed working limit of the personnel $\mathrm{D}=50 \mathrm{~mm}$ is five times safer than the permissible $9.45 \mathrm{~mm}$.

Figure 14 shows in graphical form the dangerous extent of the arc discharge. The arc ignition occurs between two parallel conductors with the current. For a circuit not equipped with an MSAE, the range of the arc flash zone reaches almost $90 \mathrm{~mm}$ from the electric arc ignition point. Activation of the MSAE arc protection system reduces the range of the hazardous zone to $9.45 \mathrm{~mm}$. The MSAE system has reduced the zone of possible arc flash hazard for technical personnel by 10 times.

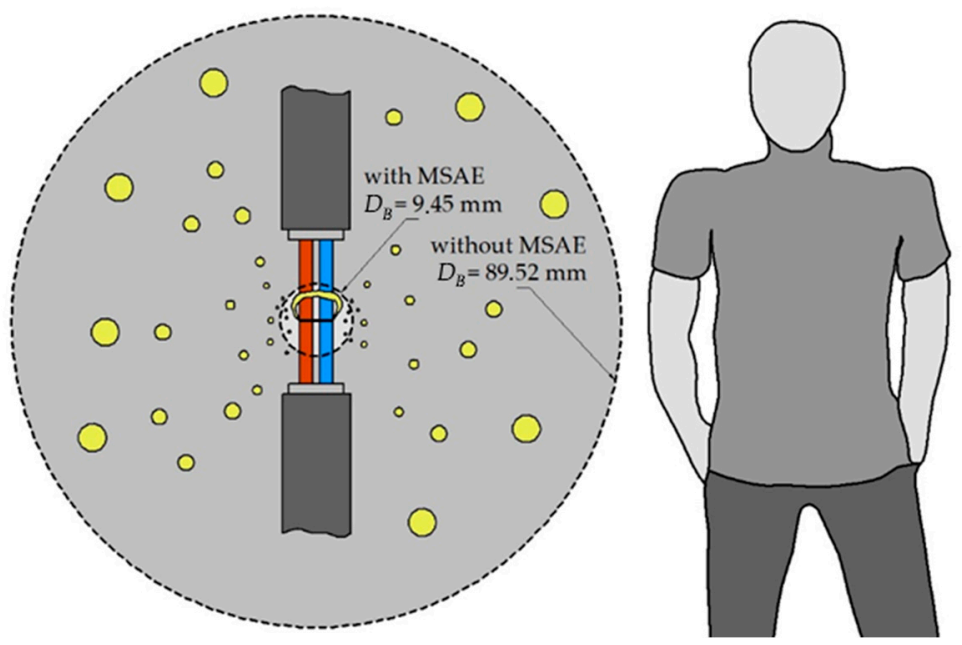

Figure 14. The emergency arc damage zone with MSAE (MSAE ON) and without MSAE (MSAE OFF).

The expected calculation parameters (according to IEEE 1584) and experimental parameters of the zones and hazard categories for the exemplary values of the arc current of 1.3/10/20 kA are presented in Table 6. For comparison with the previous calculations, the same assumptions were made:

- $C_{f}=1.5$,

- $G=3 \mathrm{~mm}$

- $K_{1}=-0.792$,

- $x=2$,

- $\mathrm{D}=50 \mathrm{~mm}$,

- three values of the arc current $I_{a}=1.3 \mathrm{kA} / 10 \mathrm{kA} / 20 \mathrm{kA}$ were adopted, 
- the duration of the arc hazard in the circuit without MASE is $t_{a}=100 \mathrm{~ms}$ and results from the own tripping times of the current breaker (CB),

- the arc hazard duration in the circuit equipped with MASE is $t_{a}=1 \mathrm{~ms}$.

Table 6. The expected calculation parameters (according to IEEE 1584) of the FPB and hazard categories for the three arc current values.

\begin{tabular}{|c|c|c|c|c|c|c|c|c|c|c|c|c|}
\hline \multirow{3}{*}{$t_{a}(\mathrm{~s})$} & \multicolumn{4}{|c|}{$I_{a}=1.3 \mathrm{kA}$} & \multicolumn{4}{|c|}{$I_{a}=10 \mathrm{kA}$} & \multicolumn{4}{|c|}{$I_{a}=20 \mathrm{kA}$} \\
\hline & \multicolumn{2}{|c|}{$D_{B}(\mathrm{~mm})$} & \multicolumn{2}{|c|}{ HRC } & \multicolumn{2}{|c|}{$D_{B}(\mathrm{~mm})$} & \multicolumn{2}{|c|}{ HRC } & \multicolumn{2}{|c|}{$D_{B}(\mathrm{~mm})$} & \multicolumn{2}{|c|}{ HRC } \\
\hline & $\begin{array}{c}\text { MSAE } \\
\text { ON }\end{array}$ & $\begin{array}{c}\text { MSAE } \\
\text { OFF }\end{array}$ & $\begin{array}{c}\text { MSAE } \\
\text { ON }\end{array}$ & $\begin{array}{c}\text { MSAE } \\
\text { OFF }\end{array}$ & $\begin{array}{c}\text { MSAE } \\
\text { ON }\end{array}$ & $\begin{array}{c}\text { MSAE } \\
\text { OFF }\end{array}$ & $\begin{array}{c}\text { MSAE } \\
\text { ON }\end{array}$ & $\begin{array}{c}\text { MSAE } \\
\text { OFF }\end{array}$ & $\begin{array}{c}\text { MSAE } \\
\text { ON }\end{array}$ & $\begin{array}{c}\text { MSAE } \\
\text { OFF }\end{array}$ & $\begin{array}{c}\text { MSAE } \\
\text { ON }\end{array}$ & $\begin{array}{c}\text { MSAE } \\
\text { OFF }\end{array}$ \\
\hline 0.001 & 22.5 & 22.5 & 0 & 0 & 67.7 & 67.7 & 1 & 1 & 98.4 & 98.4 & 2 & 2 \\
\hline 0.005 & & 50.2 & & 1 & & 151.3 & & 3 & & 220.0 & & 3 \\
\hline 0.010 & & 71.0 & & 1 & & 214.0 & & 3 & & 311.2 & & \\
\hline 0.020 & $F_{7}$ & 100.4 & $F_{7}$ & 2 & & 302.6 & $\mapsto_{7}$ & & & 440.1 & $\mapsto$ & \\
\hline 0.030 & 5 & 123.0 & 点 & 2 & 5 & 370.6 & 点 & & 点 & 539.0 & 5 & $\ddot{\bar{s}}$ \\
\hline 0.040 & $\sum_{4}$ & 142.0 & $\sum_{4}$ & 3 & $\underset{\mathbb{4}}{2}$ & 427.9 & $\sum_{\mathbb{4}}$ & $\ddot{\vec{D}}$ & $\sum_{4}$ & 622.4 & $\sum_{4}$ & 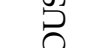 \\
\hline 0.050 & U & 158.8 & U & 3 & U & 478.4 & U & 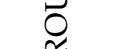 & U & 695.8 & U & $\underset{10}{2}$ \\
\hline 0.060 & $\frac{\pi}{4}$ & 174.0 & $\frac{\pi}{4}$ & 3 & $\frac{\pi}{4}$ & 524.1 & $\frac{8}{4}$ & $\frac{\underline{\underline{r}}}{\underline{\underline{T}}}$ & $\frac{\pi}{4}$ & 762.3 & 永 & 넝 \\
\hline 0.070 & 0 & 187.9 & 0 & 3 & 0 & 566.1 & 0 & Z & 0 & 823.3 & 0 & $\bar{z}$ \\
\hline 0.080 & Z & 200.9 & Z & 3 & Z & 605.2 & Z & 岩 & Z & 880.2 & Z & 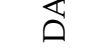 \\
\hline 0.090 & & 213.1 & & 3 & & 641.9 & & a & & 933.6 & & \\
\hline 0.100 & & 224.6 & & 3 & & 676.6 & & & & 984.07 & & \\
\hline
\end{tabular}

The undoubted advantage of using MSAE is a significant reduction of the arc time. In the present work and the work [25], it was shown that for a resistive circuit this time can be about $1 \mathrm{~ms}$. The fast tripping of the MSAE significantly reduces the energy released on the arc and thus reduces the dangerous hazard risk zone. Extending the burning time of the electric arc results in increased energy in the arc, and thus enlarges the danger zone for technical personnel.

The examples of arc flash zone and calculations of hazard risk category shown in Table 6 are intended to show the superiority of the application of the multi-sectional arc eliminator (MSAE) over the traditional time-delayed circuit breaker. The long actuation time of commonly used safety devices (to $100 \mathrm{~ms}$ ), in many cases causes the arc energy to increase to values that threaten human life. The energy values are assigned to the appropriate categories from 0 to 4 . Category 0 allows working in the vicinity of an arc fault with basic personal protection. A category increase above a value of 4 categorically prevents work in the vicinity of the arc (DANGEROUS in Table 6). In this case, the use of personal protective equipment will not adequately protect personnel from the undesirable effects of the energy released from the arc. That is why it is so important to strive to minimize the Hazard Risk Category HRC. The use of MSAE meets this requirement (reduces HRC), which significantly increases the safety of technical personnel who may be exposed to the effects of an electric arc. The use of MSAE also protects the components of the switchgear in which the electric arc was started.

The calculation results presented in Table 6 were made in accordance with the "IEEE 1584 Guide for Performing Arc-Flash Hazard Calculations" [1-5] and the assumptions adopted in this study. The example for $1.3 \mathrm{kA}$ current has been experimentally verified and its results are described above.

Analysing the calculated and presented values in Table 6, it can be noticed that for the assumed current values from $1.3 \mathrm{kA}$ to $20 \mathrm{kA}$, the use of MSAE (i.e., activation of the arc eliminator protection during $1 \mathrm{~ms}$ ) significantly reduces the hazard category. Such a time of reaction MSAE operation, which for resistive circuits is shorter than $1 \mathrm{~ms}$, in many cases will significantly reduce damage inside the switchgear in which the arc fault occurred and may even save human health or life. For the currents of $10 \mathrm{kA}$ and $20 \mathrm{kA}$, and a circuit not equipped with MSAE, the developing arc disturbance in time causes a significant increase 
of the arc energy to values exceeding the data of the category table. With energy above $40 \mathrm{cal} / \mathrm{cm}^{2}$ (category 4), the presence of technical personnel in the area of the device in which the electric arc was ignited is prohibited. For the same values of currents and the circuit protected by the MSAE system, the arc energy is limited, and the value of the hazard category ( 1 for $I_{a}=10 \mathrm{kA}$ and 2 for $I_{a}=20 \mathrm{kA}$ respectively) allows to select of appropriate protective clothing and to designate a safe zone outside the arc zone.

Figure 15 shows the characteristics of flash protection boundary $D_{B}$ as a function of the arc fault duration ta for the different current values. The calculation results from Table 3 have been presented in Figure 15 in such a way that the differences in the application of the MSAE system can be easily noticed. The curves marked with a dashed line refer to the system in which the arc fault develops for $100 \mathrm{~ms}$ until the main breaker is tripped. The same colour (solid line), for easy comparison, shows the range of the dangerous shock zone for the circuit protected with the MSAE system.

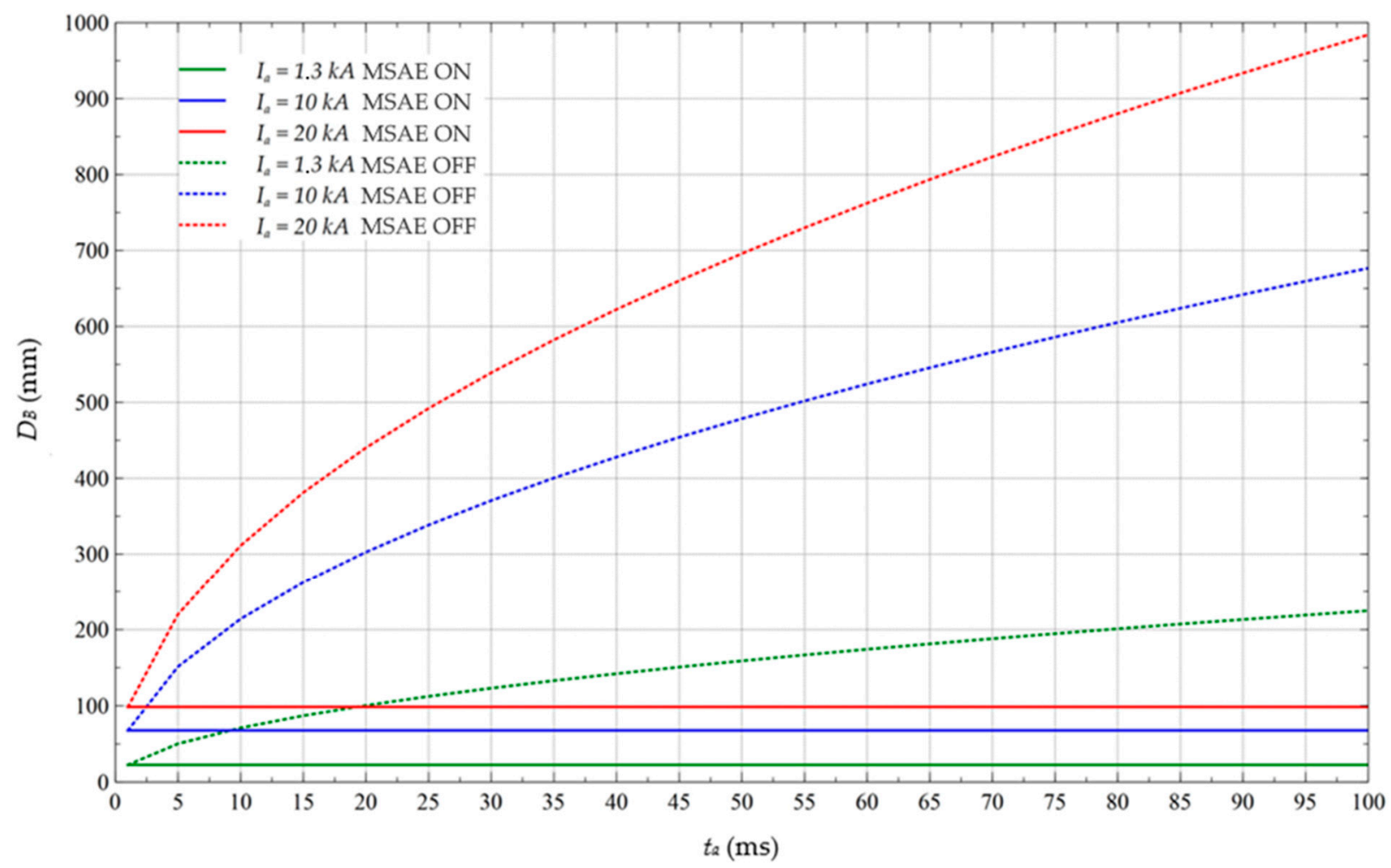

Figure 15. Characteristics of the arc flash boundary as a function of the duration of the arc disturbance for different values of the current in the circuit with the MSAE system and its absence.

When analysing Figure 15, it is important to note that triggering the MSAE in approximately $1 \mathrm{~ms}$ causes the arc to be extinguished. Eliminating the arc so quickly does not increase the energy and reduces the hazard risk.

\section{Conclusions}

The subject of the current publication and the research described in it are the results of experiments to check the effectiveness of the semiconductor module used as an electric arc eliminator. The author's project is a device enabling very quick shunting of the electric circuit affected by the arc disturbance, to create an alternative- a privileged path for the current flow. The result of this is a very fast elimination of the arisen electric arc and reduction of possible damage resulting from the developing arc disturbance.

Experimental studies presented in works $[25,26]$ showed that in circuits affected by an arc fault, sections of anti-parallel connected thyristors working as an electric arc eliminator extinguish the arc in less than $1 \mathrm{~ms}$. Reducing the duration of the arc fault significantly 
reduces the amount of energy released in the arc, resulting in a reduction of the gas pressure inside the affected switchgear. The energy reduction also significantly reduces the loss of material from the arc electrodes, and thus reduces the risk of burns to people in the vicinity of the electric arc. The results of tests and calculations confirm the effectiveness of the thyristor system as an electric arc eliminator.

The experiments carried out in similar conditions for a system without MSAE and equipped with MSAE protection clearly showed the advantages of using thyristor branches as arc protection. The arc burning time from $15.3 \mathrm{~ms}$ in the system without MSAE was reduced to $0.9 \mathrm{~ms}$, which gives the ratio $t_{M S A E}$ OFF $/ t_{M S A E O N}=17$. The arc energy of 3.83 $\mathrm{cal} / \mathrm{cm}^{2}$ by reducing the arc time decreased to a value of $0.1 \mathrm{cal} / \mathrm{cm}^{2}$. By reducing the energy by 38 times, the risk of injury from a burning arc is reduced and consequently, the hazard risk category is reduced to level 0 . The use of MSAE reduced the arc range by more than 9 times, from $89.52 \mathrm{~mm}$ to $9.45 \mathrm{~mm}$.

The values unmeasured in this work are the loss of electrodes of the arc source and the intensity of the emitted sound. Arc flares and the shipment of the electrode material droplets were recorded with a high-speed camera. In the case of many experiments, the heated remains of the electrode material are visible in the recorded photos after more than $0.5 \mathrm{~s}$ from the moment the arc is extinguished. After such a long time, burn marks at the base of the junction box were observed. As a result, a fire may start for surrounding materials and a flammable substrate. The triggering of the MSAE usually extinguishes the arc in less than $1 \mathrm{~ms}$, which limits the loss of material from the arc source electrodes and prevents possible fires. Due to the lack of a measuring device, no reduction in the sound intensity level was recorded. These measurements will be presented in the next paper. However, the authors wish to share the information that the experiments in the system without MSAE had to be performed wearing protective earmuffs, while in the system with MSAE the sound accompanying the arc discharge, within the range of test currents used, did not occur inside the tested object.

The results of the tests of the Multi-Section Arc Eliminator (MSAE), presented in this article and in $[25,26]$, confirm the undoubted advantages of using the system as a quick eliminator of the electric arc. The conducted experiments and the obtained results confirm this. The challenges that the authors set themselves are further tests of the MSAE operation for gradually increasing values of the current in the circuit. The test capabilities available to the authors are about $50 \mathrm{kA} / 50 \mathrm{~Hz} \mathrm{AC}$. In the final version, the MSAE system will cooperate with a mechanical short-circuiting switch, which in effect will constitute a hybrid short-circuiting switch. At the moment of detecting a disturbance with an electric arc, the semiconductor part of the hybrid short-circuiting switch takes over the current flow and allows time to close the contacts of the mechanical switch. A small voltage drop across the conductive sections of the MSAE will allow for arc-free closing of the high-current contacts of mechanical short-circuiting switch.

Author Contributions: Conceptualization, K.N. and J.J.; methodology, K.N. and J.J.; formal analysis, K.N., J.J. and G.D.; investigation, K.N. and J.J.; resources, K.N.; writing—original draft preparation, K.N., J.J. and G.D.; writing-review and editing, K.N., J.J. and G.D.; visualization, K.N.; supervision, K.N. and J.J. All authors have read and agreed to the published version of the manuscript.

Funding: This research was funded by the Polish Ministry of Science and Higher Education, grant number 0711/SBAD/4454.

Institutional Review Board Statement: Not applicable.

Informed Consent Statement: Not applicable.

Data Availability Statement: Not applicable.

Conflicts of Interest: The authors declare no conflict of interest. 


\section{References}

1. IEEE. IEEE Guide for Performing Arc-Flash Hazard Calculations; IEEE Std 1584-2018 (Revision of IEEE Std 1584-2002); IEEE: New York, NY, USA, 2018; pp. 1-134. [CrossRef]

2. IEEE 1584-2018-IEEE Guide for Performing Arc-Flash Hazard Calculations. Available online: https://standards.ieee.org/ standard/1584-2018.html (accessed on 17 January 2021).

3. Lippert, K.J.; Colaberardino, D.M.; Kimblin, C.W. Understanding IEEE 1584 arc flash calculations. IEEE Ind. Appl. Mag. 2005, 11, 69-75. [CrossRef]

4. Mohla, D.; Lee, W.; Phillips, J.; Marroquin, A. Introduction to IEEE Standard. 1584 IEEE Guide for Performing Arc-Flash Hazard Calculations-2018 Edition. In Proceedings of the 2019 IEEE Petroleum and Chemical Industry Committee Conference (PCIC), Vancouver, BC, Canada, 8-12 September 2019; pp. 1-12.

5. Mohla, D.; Lee, W.-J.; Phillips, J.; Marroquin, A. Introduction to IEEE Standard 1584: Guide for Performing Arc-Flash Hazard Calculations, 2018 Edition. IEEE Ind. Appl. Mag. 2020, 26, 64-76. [CrossRef]

6. Mohamed Abd Elwahab Ali_Lecture 07. IEEE 1584 Arc Flash Calculations.Pdf I Electric Arc I Electric Current. Available online: https: / / www.scribd.com/document/371508361/mohamed-abd-elwahab-ali-Lecture-07-IEEE-1584-Arc-Flash-Calculationspdf (accessed on 17 January 2021).

7. IEEE 1584 Arc Flash Calculations-Electrical Diagnostic Surveys. Available online: https://arcflashtraining.net/ieee-1584-arcflash-calculations / (accessed on 17 January 2021).

8. Majd, A.; Luo, R.; Devadass, M.A.; Phillips, J. Comprehensive Overview and Comparison of ANSI Versus IEC Short-Circuit Calculations: Using IEC Short-Circuit Results in IEEE 1584 Arc Flash Calculations. IEEE Trans. Ind. Appl. 2019, 55, 5487-5493. [CrossRef]

9. Electrical Arc Flash Hazard Management Guideline. Available online: https://www.energycouncil.com.au/media/15808/ eafhm_guideline_30_25-03-2019_web.pdf (accessed on 17 January 2021).

10. Simms, J.; Johnson, G. Protective Relaying Methods for Reducing Arc Flash Energy. IEEE Trans. Ind. Appl. 2013, 49, 803-813. [CrossRef]

11. Doan, D.R.; Sweigart, R.A. A summary of arc flash energy calculations. In Proceedings of the Record of Conference Papers. Industry Applications Society. Forty-Ninth Annual Conference. 2002 Petroleum and Chemical Industry Technical Conference, New Orleans, LA, USA, 23-25 September 2002; pp. 285-290.

12. Kazimierczak, M. ARC Faults: Operational Experiences in Industrial and Utility Power Plants. Elektroenerg. Współczesność Rozw. 2011, 2, 98-109.

13. Ventruella, D.J. Arc flash hazard-When over-estimating under-estimates a problem. In Proceedings of the 2017 Annual Pulp, Paper and Forest Industries Technical Conference (PPFIC), Tacoma, WA, USA, 18-23 June 2017; pp. 1-8.

14. Ventruella, D.J. Arc Flash Hazard-When Overestimating Underestimates a Problem. IEEE Trans. Ind. Appl. 2019, 55, 3287-3293. [CrossRef]

15. Lu, Q.; Ye, Z.; Zhang, Y.; Wang, T.; Gao, Z. Analysis of the Effects of Arc Volt-Ampere Characteristics on Different Loads and Detection Methods of Series Arc Faults. Energies 2019, 12, 323. [CrossRef]

16. Yin, Z.; Wang, L.; Zhang, Y.; Gao, Y. A Novel Arc Fault Detection Method Integrated Random Forest, Improved Multi-scale Permutation Entropy and Wavelet Packet Transform. Electronics 2019, 8, 396. [CrossRef]

17. Paul, S.; Jewell, W. Optimization Methodology for Minimizing the Arc Flash Incident Energy. In Proceedings of the 2018 IEEE Industry Applications Society Annual Meeting (IAS), Portland, OR, USA, 23-27 September 2018; p. 6.

18. Wu, H.; Li, X.; Stade, D.; Schau, H. Arc Fault Model for Low-Voltage AC Systems. IEEE Trans. Power Deliv. 2005, 20, 1204-1205. [CrossRef]

19. Kumar, P.; Kale, A.; Ranade, M. Internal arc fault simulation using CFD to predict thermal behavior in switchgear. In Proceedings of the 2017 6th International Conference on Computer Applications in Electrical Engineering-Recent Advances (CERA), Roorkee, India, 5-7 October 2017; pp. 236-241.

20. Short, T.A.; Eblen, M.L. Medium-Voltage Arc Flash in Open Air and Padmounted Equipment. IEEE Trans. Ind. Appl. 2012, 48, 245-253. [CrossRef]

21. Roscoe, G.; Valdes, M.E.; Luna, R. Methods for arc-flash detection in electrical equipment. In Proceedings of the 2010 Record of Conference Papers Industry Applications Society 57th Annual Petroleum and Chemical Industry Conference (PCIC), San Antonio, TX, USA, 20-22 September 2010; pp. 1-8.

22. Kumpulainen, L.; Hussain, G.A.; Rival, M.; Lehtonen, M.; Kauhaniemi, K. Aspects of arc-flash protection and prediction. Electr. Power Syst. Res. 2014, 116, 77-86. [CrossRef]

23. Catlett, R.; Lang, M.; Scala, S. Novel Approach to Arc Flash Mitigation for Low-Voltage Equipment. IEEE Trans. Ind. Appl. 2016, 52, 5262-5270. [CrossRef]

24. Hussain, G.A. Methods for Arc-Flash Prediction in Medium Voltage and Low Voltage Switchgear; Aalto University: Espoo, Finland, 2015; ISBN 978-952-60-6599-1.

25. Nowak, K.; Janiszewski, J.; Dombek, G. A Multi-Sectional Arc Eliminator for Protection of Low Voltage Electrical Equipment. Energies 2020, 13, 605. [CrossRef]

26. Nowak, K.; Janiszewski, J.; Dombek, G. Thyristor Arc Eliminator for Protection of Low Voltage Electrical Equipment. Energies 2019, 12, 2749. [CrossRef] 
27. Wu, H.; Li, X. Calculation of Maximum Arc Energy for Low Voltage Power Systems. In Proceedings of the 2006 IEEE PES Power Systems Conference and Exposition, Atlanta, GA, USA, 29 October-1 November 2006; pp. 1627-1630.

28. Gammon, T.; Matthews, J. Conventional and recommended arc power and energy calculations and arc damage assessment. IEEE Trans. Ind. Appl. 2003, 39, 594-599. [CrossRef]

29. Anantavanich, K.; Pietsch, G.J. Calculation of Pressure Rise in Electrical Installations Due to Internal Arcing Taking into Account Arc Energy Absorbers. IEEE Trans. Power Deliv. 2016, 31, 1618-1626. [CrossRef]

30. Low Voltage Circuit Breakers "Arc Flash Hazards" ABB. Available online: https://electrical-engineering-portal.com/res/LVArc-Flash-Paper.pdf (accessed on 10 February 2021).

31. Keller Series 21 G Piezoresistive Pressure Transmitters. Available online: http://www.keller-druck.com.pl/produkty/ przetworniki/pdf/21g_karta.pdf (accessed on 17 January 2021).

32. Kulas, S.J.; Supronowicz, H. Analiza łuku elektrycznego awaryjnego i sposoby ograniczania jego skutków. Mech. Autom. Górnictwa 2014, 52, 43-49.

33. High-Speed Camera Chronos 1.4-Datasheet. Available online: https://www.krontech.ca/wp-content/uploads/2019/03/FMENGR-50001-Chronos-1.4-Datasheet-Rv4-1.pdf (accessed on 10 February 2021).

34. Nowak, K. Photographic Registration of the Effects of the Emergency Arc in the Electrical Junction Box. Available online: https:/ / chmura.put.poznan.pl/s / 6SkIxmyG6uGYEy6 (accessed on 4 February 2021).

35. Nowak, K. Photographic Registration of Recording the Effects of an Emergency Arc from Its Ignition to the almost Complete Extinction of the Exploding, Glowing Remains of Drops of Electrode Material. Available online: https://chmura.put.poznan.pl/ s/bcENdNAktD2svbJ (accessed on 4 February 2021).

36. Nowak, K. Photographic Registration of the State of the Electrical Box during an Arc Fault in a System Equipped with an MSAE Emergency Arc Eliminator. Available online: https:/ / chmura.put.poznan.pl/s/4YYSGRYzPjuefee (accessed on 4 February 2021). 